\title{
28 Research Suare \\ Agronomic and molecular evaluation of rice lines in a breeding program
}

\section{Luis Marqués}

Copsemar

\section{Susana Barceló}

Universitat Politècnica de València: Universitat Politecnica de Valencia

José María Osca ( $\square$ josca@upv.es )

Universitat Politècnica de València: Universitat Politecnica de Valencia https://orcid.org/0000-0001-

9373-2216

\section{Original article}

Keywords: DArT, rice breeding, double haploid, QTL, rice blast, field trial design, lattice square, mixed linear model analysis, principal components analysis.

Posted Date: December 23rd, 2020

DOl: https://doi.org/10.21203/rs.3.rs-131889/v1

License: (1) (1) This work is licensed under a Creative Commons Attribution 4.0 International License. Read Full License 


\section{Abstract}

Obtaining new and improved varieties of rice requires long and complex plant breeding programs. The early detection of desirable characteristics is a complex process, especially when seeking to improve yield, as the interaction between the environment and plants may hinder selection in early generations considerably. Techniques that facilitate the selection of plants with desirable characteristics in early generations are highly valuable to plant breeders. An indirect selection method in early generations of rice was examined by principal component analysis of performance supported by field tests with a honeycomb design. This study used double haploid lines of rice obtained by crossing two rice varieties, namely 'Benisants' and 'Gigante Vercelli'. This method was compared to indirect selection using genomic tools such as high-throughput molecular marker analysis. The main factors that can be used in indirect selection have been selected by principal component analysis. The model resulting from the phenological evaluation and principal component analysis with six selected variables explained $98.73 \%$ of the total variability of yield. The variable that contributes the most to the model is the Harvest Index. The best selected lines provided $32 \%$ and $43 \%$ higher yield values than the parentals and match the results from indirect selection with molecular markers.

\section{Background}

New varieties are constantly being obtained to satisfy the needs of the rice market. Obtaining new improved varieties of rice are the result of long breeding programs, which traditionally involve extensive and expensive field trials. For this reason, the introduction in breeding programs of alternative selection methods, which allow reducing the time and cost of long field trials, are of great interest for rice breeders. The development of selection methods for evaluating qualitative and quantitative characteristics of rice in early generations is a valuable resource, both from an efficiency perspective in obtaining new varieties and from the economic standpoint, by reducing the cost of field tests. Biotechnology has been a great advance in this regard. Indirect selection in early generations through appropriate field designs is another alternative to reduce the time and cost of breeding programs. The main objective of this study was to evaluate the suitability of an indirect method for selection of yield in early generations by Principal Component Analysis. A lattice square design was used in field tests and the results were compared to those of another indirect selection method, based on high-throughput analysis of molecular markers (microarrays).

\section{Introduction}

Rice (Oryza sativa L.) is one of the most important crops worldwide. There are thousands of varieties of rice that differ in their qualitative, quantitative, agronomic and environmental adaptation characteristics. Plant breeders are continually seeking to improve some of these characteristics, which requires finding new sources of variation as a function of type of rice, production ecosystem, or environment of the new variety, as the selection characters may vary with their environment or system (Jennings et al., 1981; Aguilar et al., 2005; Cheng et al.; 2020). 
New varieties should also be adapted to a wide range of environments. However, cultivars with wide adaptability or stability are difficult to identify when the phenotypic response to environmental changes varies between study plants. The interaction between the plant or genotype and the environment (GxA) can reduce the progress of selection by making it difficult to identify potentially superior cultivars.

When selecting for desirable characteristics for rice improvement, new gains are usually obtained by crossing two varieties or pure lines of rice, which can provide sources of variation. Targeted selection is an effective, yet delicate procedure for driving genetic progress. Selection tends to focus on early generations resulting from crosses from the segregating populations, where selection for yield is prioritised and where competition between plants affects this potential (Ntanos \& Roupakias, 2001). However, rigorous pedigree selection, the limited number of plants that can be managed and GxA interactions can lead to a loss of desirable genotypes in early generations of rice. These could otherwise have been used as homozygous lines in later generations (Nagai cited by Ntanos \& Roupakias, 2001). In turn, competition between individuals in a segregating population can be intense and decrease the reliability of selection. Mass selection could therefore be more effective than pedigree selection. For these reasons, rice breeders use and adapt different selection methods in their varietal improvement programs, promoting adaption to different situations.

In other cereals, including wheat (Triticum aestivum L.) and barley (Hordeum vulgare L.), the selection of individual plants in early generations may be effective for qualitative traits but ineffective for quantitative traits such as grain yield (Nagai cited by Ntanos \& Roupakias, 2001). However, some breeders suggest that selection for high-yielding genotypes should be performed in the F2 (second filial) generation and in subsequent segregating generations (Mckenzie \& Lambert, 1961; Sneep, 1977), using suitable field designs to evaluate expression in as many genotypes as possible. For example, successful selection can be achieved when plants are adequately distributed in the field using a "honeycomb" design (Mitchell et al.,1982; Lungu et al., 1987; Fasoulas \& Fasoulas, 1995; Roupakias et al., 1997).

Selection in early generations is based on qualitative traits with high heritability that are easy to measure and evaluate. These traits can be morphological, controlled by major genes, and by some polygenic traits, such as harvest index, days to flowering, stem length, and plant type and vigor which can be evaluated and are highly heritable. In segregating populations derived from divergent parentals, visual selection may also be effective for performance components such as panicle type and size, number and size of grains per panicle, and grain fertility (Yonezawa, 1997). However, fixing these desirable characters in the selected plants requires a high number of study characters and several generations. The selection process is therefore long and expensive.

Other selection methods have been developed to accelerate the breeding process, such as those based on double haploid line (DHL) mapping, which allow fixing genetic systems of individual lines. A fast and widely used technique for obtaining DHLs is anther culture. This technique makes it possible to produce homozygous lines from segregating populations by chromosomal doubling of haploid pollen and plant regeneration, in an in vitro cultivation cycle (Lentini et al., 1977). Double haploid (DH) plants obtained 
from anther cultures are homozygous and can therefore be used directly for yield trials. The stability of characters obtained via anther culture is similar to that via conventional methods (Sugimoto \& Takeoka, 1998). However, the resulting DH plants have not undergone an evaluation and selection process for agronomic characteristics, biotic or abiotic stress, grain quality, and adaptation to a specific ecosystem. In conventional methods, by contrast, they have already been selected from a number of desirable agronomic and adaptive characteristics by the F4 or F5 generation. For this reason, DH plants are the starting point for the breeder to begin the evaluation and selection cycle. This usually starts in the R2 generation, after multiplying the small number of seeds obtained in the R1 generation. From R2, the evaluation and selection process can be performed similarly to conventional improvement methods.

Several qualitative and quantitative characters are evaluated during the improvement process. Direct selection in the first generations is difficult if performance is considered the main parameter; for this reason, methods that simplify the process are valuable. An indirect method is Principal Component Analysis (PCA), which is a variable reduction procedure used when collecting data on variables that may be related. PCA makes it possible to transform these variables into artificial components that explain most of the variance of the measured variables and may help selection in the first generations.

In field tests, performance is subject to considerable experimental error and performance components are often inversely correlated (Xing \& Zhang, 2010). Molecular techniques are especially useful when working with quantitative traits with low heritability as an alternative to field and greenhouse tests. These involve a multitude of genes with little effect and may depend on the environment. One of these techniques consists of mapping and analysing chromosomal regions to identify genes with quantitative effects (quantitative trait loci, QTL) which can be used as traceable markers throughout generations of heritable characters. QTL make it possible to relate the genotype of an organism to the expressed phenotype. Hundreds of QTL involved in the regulation of performance-related traits have been detected in rice, most linked to the grain-weight yield component. However, yield components more sensitive to environmental variations, such as variations in the number of fertile stems, are seldom mapped. For QTLs to be useful in an improvement process, they must be validated in different populations because results vary between tests and between varieties.

For rice breeders, the development of selection methods for evaluating qualitative and quantitative characteristics of rice in early generations is a valuable resource, both from an efficiency perspective in obtaining new varieties and from the economic standpoint, by reducing the cost of field tests. The main objective of this study was to evaluate the suitability of an indirect method for selection of performance in early generations by PCA. A lattice square design was used in field tests and the results were compared to those of another indirect selection method, based on high-throughput analysis of molecular markers (microarrays). To achieve this objective, selection was performed in early generations of high-yield lines derived from a DHL obtained by crossing two varieties of rice, 'Benisants' and 'Gigante Vercelli', subsequently: a) characterising the DHL molecularly by high-throughput molecular marker analysis (microarrays); b) determining the main yield-related variables or factors that can be used in an indirect 
selection process in early generations by PCA; and c) comparing two indirect selection techniques, PCA and massive molecular marker analysis (microarrays).

The use of indirect selection of yield assessed in field tests by PCA, based on the evaluation of individual plants and the comparison to indirect selection using molecular markers is a novel approach. This is a less expensive method than is commonly used by conventional seed improvement companies.

\section{Material And Methods}

Benisants' and 'Gigante Vercelli' (GV) and DH plants were cultivated from a cross between two half cycle Japonic-type rice varieties obtain their seeds, which were individually collected. The crossing was done by Copsemar (Cooperativa de Productores de Arroz, Sueca, Spain) and DH plants were obtained at the laboratory of Aula Dei Experimental Station of the CSIC (Zaragoza, Spain). 'Benisants'is a medium-height Spanish variety (Cooperativa de Productores de Semillas de Arroz, S.C.L., Copsemar) with medium-sized pearl-like grain. GV is a tall Italian variety with a large pearl-like grain. Of all the lines obtained (DHL), only those lines that initially had a similar shape and cycle adapted to the eastern part of Spain and that presented some difference with some parentals were selected. Furthermore, a small group of similar lines to GV were used because GV shows good resistance to Rice Blast (RB) disease, caused by the fungus Magnaporthe grisea (T.T. Hebert) M.E. Barr. In total, 115 target lines were selected. The 'Gleva' variety (Semillas Certificadas Castells SL) was used as the control.

Mass markers analysis (microarrays) was used for the characterisation and molecular selection of DHLs, using both the original $\mathrm{DH}$ population and the parentals. To this end, DNA was isolated from the leaves of 115 DHLs as well as from the two parentals 'Benisants' and GV, following the Diversity Arrays Technology's protocol (DArT, Yarralumla, Australia, http://www.diversityarrays.com) and then analysed on its SNP (Single Nucleotide Polymorphism) markers platform. The DNA samples of the problem rice populations (parentals and descendants from the crossing) were hybridised in a series of DNA microarrays. This was achieved by fixing a collection of more than 6,000 randomly cloned sequences in more than 50 rice varieties on glass plates. This genotyping system determines the fragments with which each problem sample is to be hybridised. The differences in hybridisation patterns reveal the genome regions that vary among the analysed samples. This technique is particularly useful for studying quantitative characters, such as germination vigour (Reinke, 2006), for which a reference panel designed by DArT is used. For the molecular characterisation, the genetic distance between each pair of individuals was calculated using the genetic distance coefficient (Nei et al., 1983) with the POPULATIONS software, v. 1.2.31, and a dendrogram created following the Neighbour-Joining method (Saitou \& Nei, 1987), implemented in the MEGA5 programme (Tamura et al., 2011).

In order to evaluate yield-related characters phenotypically, field trials were run in 2009 and 2010 in a plot covering a surface area of 1.47 ha in Sueca (Valencia, Spain). In each of the trials, the 115 DHLs, the two parental lines in duplicate and the variety 'Gleva', as a control, were compared, for a total of 121 treatments. The design of the trials was in a balanced lattice square, with the 121 treatments arranged in 
12 blocks, with the elementary plots arranged in each block in 11 rows and 11 columns, with a total of 12 repetitions for each of the lines. The elemental plots were $0.5 \times 0.5 \mathrm{~m}$ in size and contained a single plant. The area of each elemental plot was large enough to avoid competition between plants. It also allowed the maximum expression of the morphological characters that emerge in an isolated setting without restricting water supply and nutrients, and with no infections (Donald \& Hamblin, 1976; Kropff et al, 1994; Ntanos \& Roupakias, 2001). The whole trial area was surrounded by a row of parental 'Benisants' plants up to the same plantation mark to avoid the edge effect. The total surface area measured $350 \mathrm{~m}^{2}$ and the 'Fonsa' rice variety was sown in the rest of the plot. Fertilisation for the trials used $20 \mathrm{~kg}$ of complex fertiliser 27-13-10 into the preparatory soil work, which was equivalent to $154 \mathrm{~kg} \mathrm{ha}^{-1}$ of $\mathrm{N}, 74 \mathrm{~kg} \mathrm{ha}^{-1}$ of P2O5 and $57 \mathrm{~kg} \mathrm{ha}^{-1}$ of $\mathrm{K} 2 \mathrm{O}$. The plants of the different lines and varieties were obtained from seedbeds established in the first week of May. They were transplanted on 4 June during the 2009 trail and on 18 June during the 2010 trial, when plants were in the phenological BBCH 20 stage. Cultivation was conducted in line with local practices.

The parameters determined for all the plants were: height to panicle node $(\mathrm{NH})$, measured from the plant base to the main panicle node; main panicle length $(\mathrm{PL})$, obtained from the difference between the total height and $\mathrm{NH}$; number of panicles per plant (PN); grain weight per plant (GW); total plant weight (TW), calculated as the sum of GW and the straw weight value for each tested plant; harvest index $(\mathrm{HI})$, obtained as the quotient between GW and TW; and the number of days elapsed since sowing until $50 \%$ panicle emergence (DE), an indicative parameter of the cycle and each variety.

A subgroup of $55 \mathrm{DHLs}$, representative of the diversity found, were selected from the results obtained in the field tests and in the molecular characterization. A detailed characterization of the parameters related to the panicles was carried out in these $55 \mathrm{DHLs}$, and they were used in the analysis of the yield components. To this end, grains were removed from two panicles from each plant, filled grains were separated from empty ones, and the following parameters were determined: number of grains per panicle (NGP); number of filled grains per panicle (NFGP); percentage of filled grains per panicle (\%FILL); and the weight of 100 grains (W100). The Opto Rice High-Resolution Image-Processing Station was used to count and weigh grains and to measure length $(L)$, width $(W)$ and the grain $L / W$ ratio.

RB susceptibility was evaluated during the 2010 field trial as the environmental conditions that year favoured the development of the disease. In each plant, RB incidence (necrosis) in the panicle node was assessed because the damage it causes at this point is the most critical in terms of yield. To this end, the number of stems showing necrotic spots on the panicle node was counted and the percentage of harmed nodes was calculated against the total number of panicles.

The GENSTAT 12.1 software was used for statistical analysis. For each evaluated parameter, a Mixed Linear Model analysis (REML) was run. This model includes set (LINE and YEAR) and random (REPETITION, ROW, COLUMN) terms so as to ensure the analysis of all existing variability.

\section{Results}


DArT analysis yielded 465 SNPs between both parentals 'Benisants' and GV, which were unequally distributed in the 12 chromosomes. Based on these markers, a proximity dendrogram $(\mathrm{NJ})$ was obtained with 115 DHLs and the parentals. The dendrogram showed that a large proportion of DHLs was genetically closer to the 'Benisants' variety, whereas few lines were more closely related to GV (Figure 1).

In the field trials for phenotypic evaluation, rice plants were grown normally in 2009 and 2010. Evaluation of the phenological parameters of the DHLs revealed that for most DHLs, values for the evaluated parameters did not significantly differ from those observed for the 'Benisants' parental. Only a small group of lines had consistently similar values to the GV parental. This group appeared in the DArT analysis on a different main dendrogram arm from that of the other lines (Figure 1).

The complete population analysis results (121 genotypes) revealed significant differences related to the effects Year and Line in all the studied variables ( $p$-value $<0.01$ ). The Yearx Line interaction was also significant ( $p$-value< 0.01 ) for all the variables, except $P L$ and DE (Table 1). All the variables presented significant differences for the Line effect. $\mathrm{NH}$ showed the largest difference, which explains why this variable presented the largest difference between parentals. A statistically significant difference also appeared in all the parameters for the Year effect ( $p$-value<0.01). This effect can be explained by the climate differences in the crop-growing years in this test. Finally, the Yearx Line interaction (Table 1) was also significant ( $p$-value<0.01), except for two characteristics: PL and DE.

Table 1. The $\mathrm{F}$ value of the fixed effects of the joint analysis done with the 121 genotypes in

both study years according to a mixed model.

\begin{tabular}{|c|c|c|c|c|c|c|c|c|}
\hline TERM & d.f. & NH & PL & TN & GW & TW & HI & DE \\
\hline Year & 1 & $68.13^{* *}$ & $11.57^{* *}$ & $127.59^{* *}$ & $38.50^{* *}$ & $26.22^{* *}$ & $13.17^{* *}$ & $380.16^{* *}$ \\
\hline Line & 120 & $99.58^{* *}$ & $5.99 *$ & $3.14^{* *}$ & $5.39 * *$ & $7.84^{* *}$ & $18.64^{* *}$ & $16.15^{* *}$ \\
\hline Year x Line & 120 & $1.79 * *$ & $0.87 n$ & $1.60^{* *}$ & $2.57 * *$ & $2.53^{* *}$ & $2.42^{* *}$ & $1.37 \mathrm{~ns}$ \\
\hline se_d genatype & & 1.761 & 0.691 & 2.918 & 10.12 & 14.86 & $18.47 \times 10-3$ & 1.069 \\
\hline
\end{tabular}

d.f.: degrees of freedom; se_d genotype: standard error of the difference between the means of genotypes; CV: Coefficient of Variation (\%); $\mathrm{NH}$ : Height from the plant base to the node of the main panicle (in cm); PL: Mean length of the main panicle (in cm); TN: Number of stems; PW: Mean total weight of grains per plant (g); TW: Mean total weight per plant (g); HI: quotient between grain weight (GW) and total plant weight (TW); DE: Days since sowing until 50\% panicle emergence; ns: nonsignificant; * Level of significance $p<0.05:{ }^{* *}$ Level of significance $p<0.01$. 
An effective indicator of the experimental error in the trials is the Coefficient of Variation value (CV). The CV values remained low for all the variables, as also indicated by studies by Kyriakou \& Fasoulas (1985) and Fasoulas (1988). The values of most of the studied variables were below or close to $10 \%$, which confirms the effectiveness of the design and trial data.

The results of the selected subpopulations with 55 genotypes of the yield component variables (Table 2) showed that all the variables were significant ( $p$-value<0.01) for Year except for NGP. This indicated a strong genetic component in this parameter that was not affected by environmental conditions, which also occurred with the other parameters. Differences were significant for all the variables for Line and the Year $x$ Line interaction ( $\mathrm{p}$-value<0.01). For all variables in both years, results were not always normally distributed. Asymmetries appeared, given the large difference found for the parental GV compared to most lines.

Table 2. The $F$ value of the fixed effects in the joint analysis with the 55 genotypes on the performance-related component variables for both study years according to a mixed model.

\begin{tabular}{|c|c|c|c|c|c|}
\hline TERM & d.f. & NGP & NFGP & \%FILL & W100 \\
\hline Year & 1 & $4.82^{\text {ns }}$ & $8.92^{* *}$ & $15.40^{* *}$ & $45.24^{* *}$ \\
\hline Line & 90 & $13.66^{* *}$ & $8.46^{* *}$ & $5.42^{* *}$ & $9.90^{* *}$ \\
\hline Year x Line & 60 & $2.42^{* *}$ & $2.13^{* *}$ & $1.88^{* *}$ & $3.78^{* *}$ \\
\hline se_d genotype & - & 7.533 & 7.597 & 2.036 & $70.04 \times 10^{-3}$ \\
\hline CV & - & 11.0 & 12.1 & 4.9 & 4.7 \\
\hline
\end{tabular}

d.f..: degrees of freedom; NGP: mean number of total grains per panicle; NFGP: mean number of total filled grains per panicle; \%FILL: percentage of filled grains versus total grains per panicle; W100: Weight of 100 grains $(\mathrm{g})$; se_d genotype: standard error of the difference between the means of genotypes; CV: Coefficient of Variation (\%); ns: non-significant; *Level of significance $p<0.05$; ** Level of significance $p<0.01$.

Height to panicle node $(\mathrm{NH})$. This characteristic presented very high heritability with a very low standard error for the difference found. It was thus considered very stable and not influenced by environmental effects. Three clearly different groups were found among the Lines within a range of measures that varied from $52.36 \mathrm{~cm}$ to $95.08 \mathrm{~cm}(50-60 \mathrm{~cm}, 65-70 \mathrm{~cm}, 80-95 \mathrm{~cm})$. Most tested lines gave low values, included the reference 'Gleva' variety and the parental 'Benisants'. The rest of the lines had a significantly different $\mathrm{NH}$ to this large group, which was a similar group to the other parental, GV, and a small intermediate group (Figure 2).

Main panicle length $(P L)$. The reference variety 'Gleva' exhibited the lowest PL value in both trial years $(13.32 \mathrm{~cm})$ versus the parental GV and its maximum value $(20.43 \mathrm{~cm})$. The other parental, 'Benisants', 
was among the mean values, between 'Gleva' and GV. The difference between the two extremes implied a $53 \%$ increase for PL. The obtained values suggest a positive asymmetric distribution with similar values among all the tested lines, but the parental GV and some similar lines did not come close to the other lines (Figure 3).

Number of panicles per plant $(P M)$. Significant differences were obtained in the values corresponding to $\mathrm{PN}$, with a difference of $33 \%$ between the extreme values. The standard error of the difference in means was very high and the observed heritability was the lowest. These results imply that this variable has a very strong environmental effect and no differences could be concluded between both parentals (Figure 4).

Grain weight per plant (GW). This was the most important crop outcome variable. Significant differences were found between the two study years; the mean values obtained in 2010 were $20 \%$ lower than those obtained in 2009. In 2009, the maximum values were nearly double the minimum values. In 2010 , however, this difference was smaller and ranged up to $60 \%$. This could result from differences in the transplanting dates and the more favourable climate conditions for crop growing in 2009. The standard error of the difference was also high, which indicates wide variability between the measured values and relatively low heritability. The values ranged between $90.01 \mathrm{~g}$ and $161.19 \mathrm{~g}$, with a difference of $79 \%$ (Figure 5).

Total plant weight (TW), or total biomass. This parameter has been indicated by some researchers as a reference to select genotypes. The values corresponded to the GW values, with a $78 \%$ difference between the maximum $(268.64 \mathrm{~g})$ and minimum $(150.31 \mathrm{~g})$ values. The two factors Year and Line and their interaction were significant ( $p$-value $<0.01$ ), as indicated for the $G W$ variable, because both variables were related. This interaction indicated the different performance of the lines in terms of plant GW and TW according to the environmental conditions. In 2009, the maximum values were nearly double the minimum values, while the difference between them reached $70 \%$ in 2010 . Most of the lines were grouped between both parentals, and were biased towards one of the two, which was 'Benisants' in this case (Figure 6).

Harvest Index (HI). This parameter measures efficiency in grain production compared to the produced total biomass. The standard error of the difference was low and heritability was high (88\%), which indicates that this could be an reliable and stable indirect parameter to evaluate the productive potential of an improvement line. The difference between the minimum and maximum values was $65 \%$. The values displayed discontinued progression with the parental GV at the very bottom of the graph and were isolated from those for the other lines, and most of the remaining lines had similar values to the other parental 'Benisants' (Figure 7).

Days until $50 \%$ panicle emergence (DE). This parameter has been very stable in this population, with the lowest CV and standard error values, and with very high heritability. The combination of the three indicators confirmed that this parameter is one of the most stables under similar crop-growing conditions. Indeed, no significant interaction appeared in this parameter, which meant that the lines had a 
similar cycle, despite the differing environmental conditions. Nonetheless, they did differ in the two years studied. Most of this series of lines presented biased values towards the parental 'Benisants' (97.13 days) and with lower values, while the values were higher for the variety GV (109.17 days). A small group was genetically similar to GV with values intermediate between both groups (Figure 8).

100-grain weight (W100). This parameter was stable. Here the effect of Year and Line, and the interaction of both, was statistically significant ( $p$-value $<0.01$ ). The values of the lines followed a normal distribution, except for three lines with abnormally low and different values from those of the two parentals. A $26 \%$ difference was found between the line with the minimum value and that with the maximum value. In the case of the two parents, there were no differences between the two ( $3.35 \mathrm{~g}$ for variety 'Benisants' and 3.47 $\mathrm{g}$ for variety GV) (Figure 9).

Number of grains per panicle (NGP) and Number of filled grains per panicle (NFGP). These two parameters behaved similarly, as the corresponding histograms indicate (Figures 10 and 11). These characteristics are closely related and are considered two of the most important yield components. The values obtained were relatively stable during the two-year study period. The distribution of this characteristic between the lines on the average of years was asymmetric on the right as the group of genetically similar lines to the parental GV obtained the highest values, while showing discontinuity for the other lines. The difference between the minimum and maximum values for these parameters was notably high: $61 \%$ in NGP, and 58\% in NFGP (Figures 10 and 11 ).

Mean percentage of filled grains per panicle (\%FILL). This parameter indicates the relationship between the two previous parameters, namely NGP and NFGP. The mean relationship between NFGP and NGP was $91 \%$. The differences observed between Lines and Years in the trial were statistically significant, as was the Year $x$ Line interaction ( $p$-value $<0.01$ ). This characteristic presented an asymmetric distribution to the left, caused by the lower percentages that the few more similar lines to the parental GV presented. Most lines were similar to the parental 'Benisants' (Figure 12).

Necrosis on the panicle node. Minimum values were obtained by the subgroup that was genetically more similar to the parental GV and the highest values were observed in the reference variety 'Gleva' with a 10fold higher value. The parental variety 'Benisants' was among the mean values. Although the results could be evaluated in 2010 only, analysis of variance (ANOVA) revealed some significant differences among the lines ( $p$-value< 0.01) (Table 4), which confirmed that the design employed in the trial was capable of discriminating the lines more sensitive to pyricularia, even though the employed plantation mark did not simulate normal crop-growing conditions (Figure 13). 
Table 3. The $\mathrm{F}$ value of the fixed effects of the joint analysis of 121 genotypes, on the variable

Necrosis on the Panicle Node, in one year, according to a mixed model.

\begin{tabular}{|c|c|c|}
\hline TERM & d.f. & NECROSIS \\
\hline Line & 120 & $2,78^{* *}$ \\
\hline se_d genotype & - & 0.828 \\
\hline
\end{tabular}

d.f.:: degrees of freedom; NECROSIS: mean number of main panicle nodes affected by Rice Blast; se_d genotype: standard error of the difference between the means of genotypes; *Level of significance $\mathrm{p}<0.05 ;{ }^{*}$ Level of significance $\mathrm{p}<0.01$.

Table 4. Values of the main characteristics obtained in the parental varieties, the reference variety and the two lines with better results.

\begin{tabular}{|l|c|c|c|c|c|}
\hline & 96 & 99 & 'BENISANTS' & 'GV' & 'GLEVA' \\
\hline $\begin{array}{l}\text { Height to panicle node (NH) (in } \\
\text { cm) }\end{array}$ & 88.66 & 88.44 & 57.54 & 95.08 & 54.83 \\
\hline Number of panicles (PN) & 40.17 & 40.27 & 37.38 & 34.70 & 43.62 \\
\hline Total weight (TW) (g) & 268.64 & 266.88 & 174.67 & 227.83 & 191.47 \\
\hline $\begin{array}{l}\text { Number of grains per panicle } \\
\text { (NGP) }\end{array}$ & 174 & 196 & 139 & 176 & 145 \\
\hline Number of filled grains (NFGP) & 153 & 177 & 128 & 144 & 128 \\
\hline$\%$ filled grains (\%FILL) & 88.43 & 90.32 & 92.16 & 82.25 & 88.17 \\
\hline Harvest Index (HI) & 0.59 & 0.59 & 0.62 & 0.40 & 0.63 \\
\hline Weight 100 seeds (W100)(in g) & 3.58 & 3.50 & 3.35 & 3.47 & 3.19 \\
\hline Grain weight (GW) (g) & 161.19 & 160.10 & 108.24 & 91.20 & 120.42 \\
\hline
\end{tabular}

The 55 DHLs selected according to DArt (Figure 1) and field trials to characterise the yield-related components, which were representative of the found genetic diversity, were: $7,8,11,13,14,15,17,22,24$, $29,30,33,35,36,38,39,41,43,46,47,49,50,51,53,54,56,57,59,63,65,66,68,69,72,74,79,80,82$, $83,85,90,91,92,93,96,97,98,99,106,109,110,111,112,114$ and 115 . The PCA of the results provided the weights of all the variables in the corresponding principal components (PCs) (Table 6). The first three 
PCs explained $82.74 \%$ of the total variance for nine evaluated characters of a population with 58 lines. The high variance related to the variables included in these three PCs provide an insight into their use in successive improvement programmes.

Table 5. Analysis of the correlations among all the variables (performance components and grain performance), calculated on the 55 DHLs, parentals 'Benisants' and 'Gigante Vercelli,' and the reference variety 'Gleva'.

\begin{tabular}{|l|c|c|c|c|c|c|c|c|c|}
\hline & NH & TN & NGP & NFGP & $\%$ FILL & W100 & TW & HI & GW \\
\hline Node height (NH) & & $\mathrm{nc}$ & +++ & +++ & - & $\mathrm{nc}$ & +++ & - & ++ \\
\hline Total no. (PN) & $\mathrm{nc}$ & & $\mathrm{nc}$ & $\mathrm{nc}$ & $\mathrm{nc}$ & $\mathrm{nc}$ & + & $\mathrm{nc}$ & ++ \\
\hline No. grain (NGP) & +++ & $\mathrm{nc}$ & & +++ & -- & $\mathrm{nc}$ & +++ & -- & ++ \\
\hline $\begin{array}{l}\text { No. filled grain } \\
\text { (NFGP) }\end{array}$ & +++ & $\mathrm{nc}$ & +++ & & - & $\mathrm{nc}$ & +++ & - & ++ \\
\hline \%FILL & -- & $\mathrm{nc}$ & - & - & & $\mathrm{nc}$ & - & ++ & $\mathrm{nc}$ \\
\hline W100 & $\mathrm{nc}$ & $\mathrm{nc}$ & $\mathrm{nc}$ & $\mathrm{nc}$ & $\mathrm{nc}$ & & $\mathrm{nc}$ & + & $\mathrm{nc}$ \\
\hline Total weight (TW) & +++ & + & +++ & +++ & -- & $\mathrm{nc}$ & & - & +++ \\
\hline Harvest index (HI) & +++ & $\mathrm{nc}$ & - & ++ & -- & + & - & $\mathrm{nc}$ \\
\hline Grain weight (GW) & ++ & ++ & ++ & ++ & $\mathrm{nc}$ & $\mathrm{nc}$ & +++ & $\mathrm{nc}$ & + \\
\hline
\end{tabular}

nc No correlation

Poor correlation: $\mathrm{r}=0$ a $0.35 / / 0 \mathrm{a}$

$+/ /--0.35$

Moderate correlation: $r=0.36$ a $0.67 / /-0.36$

$++/ /--$ a -0.67

Good correlation: $r=0.68$ a $1.00 / /-0.68 \mathrm{a}-$

$+++/ /--1.00$ 
Table 6. Table of the weights of the variables evaluated in the first four principal components

(PCs) for the population's 58 varieties.

\begin{tabular}{|l|r|r|r|}
\hline CHARACTER & Component 1 & Component 2 & Component 3 \\
\hline NH & 0.446838 & -0.0665813 & 0.0569649 \\
\hline TN & 0.0111885 & 0.466577 & -0.583468 \\
\hline NGP & 0.444269 & -0.0300101 & 0.0714792 \\
\hline NFGP & 0.40904 & 0.0589391 & 0.0429931 \\
\hline \%FILL & -0.285189 & 0.304475 & -0.108769 \\
\hline W100S & -0.0786169 & 0.308932 & 0.788573 \\
\hline TW & 0.429124 & 0.255421 & -0.0425595 \\
\hline HI & -0.318254 & 0.415406 & 0.103699 \\
\hline GW & 0.250151 & 0.589535 & 0.0558608 \\
\hline
\end{tabular}

\section{Discussion}

In principle, a DHL population shows the expected genetic variability of one F2 generation (Lentini et al., 1997). The large proportion of DHLs closer to the 'Benisants' variety can be explained by the crossing of 'Benisants' $x$ GV, which sought to incorporate certain characteristics of GV into the 'Benisants' variety, such as a larger grain, longer panicles, more grains per panicle, and better tolerance to pyricularia.

Rice plant growth is dependent on environmental conditions, specifically temperature, to a great extent. Climate conditions differed during the two-year period (2009-2010) when the trials took place. The low minimum temperatures when crop growing started during the 2010 field trial affected the growth of the lines, which resulted in less vigorous plant development and tillering. As observed by other authors (Guimaraes, 2009), some parameters can be affected by environmental conditions, specifically temperature variations. When temperatures increased, plants presented better tillering. Heat variation also differed in both study years, with maximum temperature values in May and August higher in 2010 than 2009 , which could have influenced plant development in both years. Another difference was total annual rainfall, with higher levels of $798.5 \mathrm{~mm}$ in 2009 compared to $542.1 \mathrm{~mm}$ in 2010. Rainfall in September 2009 was particularly relevant as several study plants were lost in this period. However, the higher frequency of rainy days at the end of August and in September 2010 provided more favourable conditions for RB to appear, which coincided with rice maturation.

The environment influences all heritable characters. The concept of heritability represents what proportion of phenotypic variance is due to genotypic variance. We observed that the most stable variables and those with higher heritability were $\mathrm{NH}$ and $\mathrm{DE}$, whose values exceeded $90 \%$, while $\mathrm{PN}$ and GW were affected mostly by environmental conditions and would therefore not be suitable for directly selecting genotypes. 
Once the genetic heritability of the different traits and the correlations between them have been obtained, it will be easier to increase total yield using indirect selection through the yield components (Diz \& Schank, 1995; Rebetzke et al., 2002; Ukaoma et al., 2013). The analysis of the yield components using the mixed model that combined the results obtained in the two consecutive field trial years, provided medium values for the main characteristics of each evaluated line and revealed statistically significant differences between the selected DHL. Yoshida (1983) reported the following heritability values: TN 54\%; NGP 88\%; $\%$ FILL 83\%; W100 73\%. These values indicate that these three main yield components could be used in an improvement programme and the percentage of the character remaining among generations would be high. The two lines with the highest GW values of $161.19 \mathrm{~g}$ and $160.10 \mathrm{~g}$, respectively, were those corresponding to 96 and 99, which did not significantly differ from one another (Table 4). Increased yield could be achieved with either increased biomass production (TW) or HI (Khush, 1995, Cheng et al., 2020), which was previously the case with the reference variety 'Gleva', where this increase was achieved by a high grain-straw ratio. However, the two selected lines with better grain performance (96 and 99) showed a major increase in TW (biomass) compared with parentals 'Benisants' and GV (Table 4), in line with findings for hybrid rices (Song et al., 1990; Yamauchi, 1994; Peng et al., 2000).

The $\mathrm{NH}$ value of these two better performing lines were similar to those of the parental GV. These values were high, which can make using these lines as a variety under the current crop-growing conditions difficult as they could be susceptible to early embedding. Resistance to embedding is one of the main selection objectives in the improvement programmes run in Spain today. For NT, the selected lines presented high and intermediate values between the parental 'Benisants' and the reference variety 'Gleva'. The TW values found in the selected lines were higher by $40 \%$ than those of the parentals and the reference variety 'Gleva', indicating a relationship between increased biomass and grain yield. For $\mathrm{HI}$, the only variety with a very low $\mathrm{HI}$ value was GV, due to its height, resulting in a high weight value in the vegetative part for grain performance, which was the lowest of the series of lines.

Major differences were found in the NFGP value between selected lines 96 and 99 (153 and 177 respectively) and the parental 'Benisants' and the reference variety 'Gleva' (128 in both, indicative of short panicles), which implied increases of $19.5 \%$ and $38 \%$, respectively. The parental GV had an intermediate value (144).

Progression was also noted among the values for W100, with the 'Gleva' variety showing the lowest value and trial lines 96 and 99 higher values, which were close to those for the parental GV. The difference between the mean of the two lines and that of the 'Gleva' variety was $11 \%$. The values of the trial lines were similar to that for the parental GV, with which they shared genetic similarities.

For some characteristics, similarities were observed between the lines belonging to the same dendrogram arm where the variety GV was located (Fig. 1). For two of the four evaluated characteristics, a similar and clearly differentiated group formed that shared values with almost all the lines that belonged to the same dendrogram arm obtained in the DArT analysis (90, 92, 93, 96, 97, 98 and 99 in Fig. 1). 
It proved useful to study the correlations between the evaluated variables to identify the variables that best predicted grain performance for indirect selection purposes (Table 5). The correlation coefficients between each pair of variables obtained within the -1 to +1 range measured the strength of the linear relationship among the variables. Based on these correlations, we can state that $\mathrm{GW}$ increased in this population with TW and its related characters: higher NH, PN, and NGP. This is in agreement with previous findings (Song et al., 1990; Yamauchi, 1994; Peng et al., 2000).

The PCA provided the weights of all the variables in the corresponding PCs. The first component explained almost $50 \%$ of the total variance. The variables that correlated positively with this first component were $\mathrm{NH}, \mathrm{PN}, \mathrm{NFGP}$, and TW and those inversely correlated were $\mathrm{HI}$ and \%FILL; i.e. phenological variables and grain performance-related variables. This component is clearly and specifically related to "plant size and its vegetative development" and to yield, which corroborates the aforementioned relationship between plant size and grain yield. Similar results were obtained by Kayode et al. (2008), Sanni et al. (2012) and Nachimuthu et al. (2014). The second component explained $21.45 \%$ of variance and was related to $\mathrm{GW}$, this being the main variable, and to $\mathrm{PN}$, which reflects the close relationship between both characters. This was followed by $\mathrm{HI}$. This component was related more with the grain performance variables and the plant's GW/TW ratio than with plant size and can facilitate the identification of lines with higher yield values. The first two PCs sum almost three quarters of the total estimated variability. The third component explained $11.32 \%$ of variance, and was related closely with W100 and inversely correlated with PN. This component is related to grain size.

Based on the results obtained from the evaluation of the morphological parameters and yield in the field/laboratory, 58 lines were classified using a dendrogram (Fig. 15), where four groups were categorized. The first group was composed only of the parental $G V$, the second of lines 90,92 and 93, the third of lines 96, 97, 98 and 99, and the fourth of the other lines, along with the parental 'Benisants' and the reference variety 'Gleva'. These groups resulted from hierarchical cluster analysis, with similar results to those obtained with the PCA (Fig. 14). This finding demonstrates the relationship between both analysis types, as indicated by other authors (Shaibu \& Maji, 2012).

Multiple linear regression analysis with all the evaluated variables (NH, PN, NGP, NFGP, \%FILL, TW, W100, $\mathrm{HI}$ ) is a useful tool to study variables that best predict GW. Variables $\mathrm{NH}$ and PN were ruled out when generating the model because they were not statistically significant. The equation of the adjusted model that describes the relationship between GW and the six significant independent ( $p$-value $<0.05)$ variables is:

$G W=-14.9693+0.916703 * N F G P-0.829354 * N G P-1.41359 * \% F I L L+0.611113 * T W+4.00042 * W 100+$ $212.653 * H I$

The model's R-squared fit was $98.73 \%$, which indicates that the variability of the retained predictor variables explained $98.73 \%$ of the total variability of GW. In this model, the most relevant predictor variable was the $\mathrm{Hl}$; the higher the $\mathrm{HI}$, the heavier the $\mathrm{GW}$. Other variables positively correlated with $\mathrm{GW}$ are 
NFGP, TW and W100. However, NGP and \%FILL were negatively related; i.e., the combination of a higher NGP and a higher \%FILL, but a lower GW, is possible.

\section{Conclusions}

In conclusion, the experimental design of a lattice square and a plantation mark in an isolated setting ( 0.5 $x 0.5 \mathrm{~m}$ ) allowed the expression of morphological characters, as well as the phenological and productive characterisation of the family of DHLs. Our evaluation allowed us to understand performance in the field and to select the best genotypes. The DaRT analysis enabled us to classify lines genetically and confirmed the previous selection of lines that were more phenotypically similar to the parental 'Benisants', except for a few DHLs whose characters were more like the parental GV.

The two most outstanding DHLs in the population obtained $32 \%$ and $43 \%$ higher yield values than the parentals 'Benisants' and GV, respectively. This indicates a transgressive inheritance phenomenon over the two parentals.

Grain yield showed the highest positive correlation with the plant's TW and more moderate positive correlations with PN, NFGP and NH and number of stems which, along with W100 and HI, predicted the best results, especially the mean GW per plant.

The heritability values we obtained were very high for some of the main characters, which confirmed the indirect selection theory as opposed to direct yield selection. The highest values were found in $\mathrm{HI}, \mathrm{DS}$, NGP and NFGP.

The cluster analysis performed using the data obtained from the 2009 and 2010 field trials was similar to the dendrogram created with the genetic analysis done of the population. This will assist in validating the lattice square design method in an isolated setting, as it is capable of obtaining the phenotypical differentiation of the genotypes to be tested.

\section{Abbreviations}

Analysis of variance (ANOVA), Coefficient of Variation (CV), Days until 50\% panicle emergence (DE), Diversity Arrays Technology (DArT), Deoxyribonucleic acid (DNA), Double haploid (DH), Double haploid line (DHL), Second filial (F2), Genotype x Environment (GxE), Grain length (L), Gigante Vercelli (GV), Grain length/width ratio (L/W), Grain weight per plant (GW), Grain width (W), Harvest index (HI), Height to panicle node (NH), International Rice Research Institute (IRRI), Main panicle length (PL), Mixed Linear Model analysis (REML), Number of days elapsed since sowing until $50 \%$ panicle emergence (DE), Number of filled grains per panicle (NFGP), Number of grains per panicle (NGP), Number of panicles per plant (PN), Percentage of filled grains per panicle (\%FILL), Principal component (PC), Principle Components Analysis (PCA), Quantitative trait locus (QTL), Rice Blast (RB), Single nucleotide polymorphism (SNP), Total plant weight (TW), Weight of 100 grains (W100). 


\section{Declarations}

\section{Ethics approval and consent to participate}

Not applicable

\section{Consent for publication}

Not applicable

\section{Availability of Data and Materials}

All data generated or analysed during this study are included in this published article [and its supplementary information files].

\section{Competing interests}

The authors declare that they have no competing interests.

\section{Funding}

The authors received no specific funding for this work. It has been carried out using own resources of the Cooperativa de Productores de seed de arroz (COPSEMAR) and the Polytechnic University of Valencia (Spain).

\section{Authors' contributions}

Conception and design: LM and JMO. Field trials: LM. Statistical analysis: LM and SB. Interpretation of results, draft and revision: $L M, S B$, and JMO.

\section{Acknowledgements}

The authors would like to thank the Cooperative of Rice Seed Producers (Cooperativa de Productores de Semilla de Arroz - COPSEMAR) for allowing us to conduct the field tests at their facilities and for supplying plant material. They also thank the Aula Dei Experimental Station (Estación Experimental de Aula Dei - EEAD) of the Spanish National Research Council (Consejo Superior de Investigaciones Cientificas - CSIC; Zaragoza, Spain) for their help in obtaining the Double Haploid Line (DHL).

The authors received no specific funding for this work.

\section{Authors' information}

a Luis Marqués. Agronomist PhD, specialist in rice breeding. Director of Copsemar. Copsemar is a company dedicated to the breeding, production and commercialization of rice seeds. It is the main rice seed producer in Spain. 
${ }^{b}$ Susana Barceló. Agronomist PhD, Associate Professor of the Department of Applied Statistics and Operational Research and Quality, Polytechnic University of València. Specialist in statistical methos and multivariate analysis.

${ }^{c}$ José M Osca. Agronomist PhD, Associate Professor of the Department of Plant Production Polytechnic University of València. Specialist in rice production and weed managment.

Orcid ID: 0000-0001-9373-2216

\section{References}

Aguilar, M., Castejon M. \& Alvarez, L. (2005). Identificacion de las razas de Pyricularia oryzae en la zona arrocera de las Marismas del Guadalquivir [Identification of the races of Pyricularia oryzae in the ricegrowing area of the Guadalquivir tidal marshes] (2005). Junta de Andalucia, Consejeria de Agricultura y Pesca [Ministry of Agriculture and Fisheries].

Cheng, F., Quan, X., Zhengjin, X. \& Wenfu, C. (2020) Effect of Rice Breeding Process on improvement of Yield and Quality in China. Rice Science, 27: 363-367.

Diz, D.A., \& Schank S.C. (1995). Heritabilities, genetic parameters, and response to selection in pearl millet x elephantgrass hexaploid hybrids. Crop Sci. 35: 95-101.

Donald, C.M. \& Hamblin, J. (1976). The biological yield and harvest index of cereals as agronomic and plant breeding criteria. Adv Agron 28: 361-405.

Fasoulas, A.C., (1988). The honeycomb methodology of plant breeding. Published by the author, Thessaloniki, Greece, 197 pp.

Fasoulas, A.C. \& Fasoulas V.A., (1995). Honeycomb selection designs. Plant Breed. Rev. 13: 87-139.

Guimaraes, E.P. (2009). Rice breeding. In Handbook of plant breeding. Vol 3: Cereals, Ed M.J. Carena, Springer, Berlin/Heidelberg, Alemania.

Jennings, P.R., Coffman, W.R. \& Kauffman, H.E. (1981). Mejoramiento de arroz. Centro Internacional de Agricultura Tropical, CIAT. Cali, Colombia.

Kayode, S.A., Fawole, I., Guei, R.G., Ojo, D.K., Eklou, S.A. \& Daniel T.D. (2008). Geographical patterns of phenotypic diversity in Oryza sativa landraces of Côte d'Ivoire. Euphytica 160: 389-400.

Khush G.S. (1995). Breaking the yield frontier of rice. GeoJourna/ 35:329-332.

Kropff M.J., Kassman K.G., Peng S. \& Matthews R.B. (1994). Quantitative understanding of yield potential. In Cassman, K.G. Ed; Breaking the yield barrier. International Rice Research Institute, Manila, Filipinas. 
Kyriakou, D.T. \& Fasoulas, A.C. (1985). Effects of competition and selection pressure on yield response in winter rye (Secale cereale L.). Euphytica 34: 883-895.

Lentini, Z., Martínez, C. \& Roca W. (1997). Cultivo de anteras de arroz en el desarrollo de germoplasma. Publicación CIAT No 293, ISBN 958-9439-92-6, Agosto 1997. Fundación Polar, CIAT y Fundación Rockedeller, p 50.

Lungu, D.M., P.J. Kaltsitkes \& Larter, E.N. (1987). Honeycomb selection for yield in early generations of spring wheat. Euphytica 36: 831-839.

Mckenzie, R.I.H. \& Lambert J.W. (1961). A comparison of F3 lines and their related F6 lines in two barley crosses. Crop Sci.1: 246-249.

Mitchell, J.W., Baker, R.H. \& Knott, D.R. (1982). Evaluation of honeycomb selection for single plant yield in durum wheat. Crop Sci. 22: 840-843.

Nachimuthu, V.V., Robin, S., Sudhakar, D., Raveendran, M., Rajeswari S. \& Manonmani, S. (2014). Evaluation of Rice Genetic Diversity and Variability in a Population Panel by Principal Component Analysis. Indian Journal of Science and Technology 7: 1555-1562.

Nei, M., Maruyama T. \& Wu C.I., (1983). Models of evolution of reproductive isolation. Genetics 103: 557579 .

Ntanos, D.A. \& Roupakias, D.G. (2001). Comparative efficiency of two breeding methods for yield and quality in rice. Crop Science 41, 345-350.

Peng S, Laza RC, Visperas RM, Sanico AL, (2000). Grain yield of rice cultivars and lines developed in the Philippines since 1966. Crop Science 40: 307-314.

Rebetzke, G. J., Condon, A. G., Richards, R A. \&. Farquhar, G. D. (2002). Selection for reduced carbon isotope discrimination increases aerial biomass and grain yield of rainfed bread wheat. Crop Sci. 42: 739745.

Reinke, R. (2006). Evaluating Diversity Array Technology (DArT) for the NSW Rice Breeding Program. Rural Industries Research and Development Corporation.

Roupakias, D., Zesopoulou, A., Kazolea, S., Dalkalitses, G., Mavromatis, A. \& Lazaridou, T. (1997). Effectiveness of early generation selection under two plant densities in faba bean (Vicia faba L.). Euphytica 93: 63-70.

Saitou, N. \& Nei, M. (1987). The neighbour-joining method: A new method for reconstructing phylogenetic trees. Mol. Biol. Evol. 4: 406-425. 
Sanni K.A., Fawole I., Ogunbayo S.A., Tia D.D., Somado, E.A., Futakuchi, K., Sié, M., Nwilene, F.E. \& Guei R.G. (2012). Multivariate analysis of diversity of landrace rice germplasm. Crop Science 52: 494-504.

Shaibu A.A. \& Maji A.T. (2012). Application of principal component analysis for rice germplasm characterization and evaluation. Journal of Plant Breeding and Crop Science 4(6): 87-93.

Sneep, J. (1977). Selecting for yield in early generation of self-fertilizing crops. Euphytica 26: 27-30.

Song, X.F., Agata, W. \& Kawamitsu, Y. (1990). Studies on dry matter and grain production of F1 hybrid rice in China. I. Characteristic of dry matter production. Japanese Journal of Crop Science 59: 19-28.

Sugimoto, K. \& Takeoka, Y. 1998. Genetic analysis of plant regeneration ability in anther culture of rice (Oryza sativa L.) Breed Sci 48: 115-121.

Tamura, K., Peterson D., Peterson N., Stecher G., Nei M., \& Kumar S. (2011). MEGA5: Molecular Evolutionary Genetics Analysis Using Maximum Likelihood, Evolutionary Distance, and Maximum Parsimony Methods. Molecular Biology and Evolution 28: 2731-2739.

Ukaoma, A.A., Okocha, P.I. \& Okechukwu, R.I. (2013). Heritability and character correlation among some rice genotypes for yield and yield components. J. Plant Breed. Genet. 1 (02): 73-84.

Xing, Y. \& Zhang, Q. (2010). Genetic and Molecular Bases of Rice Yield. Annual Review of Plant Biology 61: 421-442.

Yamauchi, M (1994). Physiological bases of higher yield potential in F1 Hybrids. In SS. Virmani ed. Hybrid rice technology: New developments and future prospects: 71-80. International Rice Research Institute. Los Baños, Filipinas.

Yonezawa, K. (1997). Yield components. In T. Matsuo, Y. Futsuhara, F. Kikuchi, H. Yamaguchi; Eds, Science of the Rice Plant, III, Genetics, Food and Agriculture Policy Research Center, Tokyo: 400-412.

Yoshida, S. (1983). Rice. In Smith, W.H. \& Banta, S.J., Eds., Potential productivity of field crops under different environments. International Rice Research Institute, Los Baños, Filipinas:103-127.

\section{Figures}




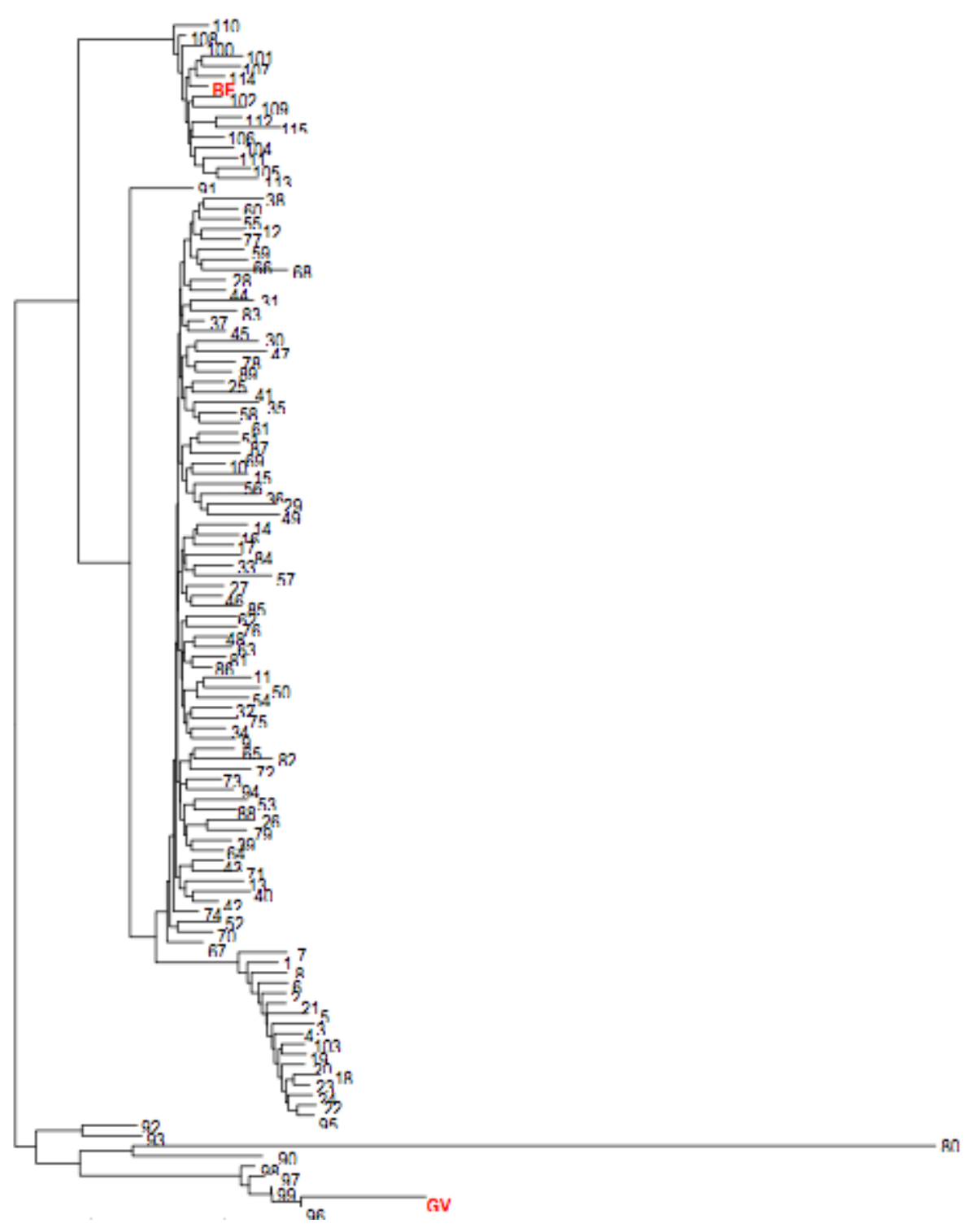

Figure 1

Proximity dendogram $(\mathrm{NJ})$ built using the estimated genetic distance among the 115 Double haploid lines (DHL) and their two parentals, 'Benisants' (BE) and 'Gigante Vercelli '(GV). 


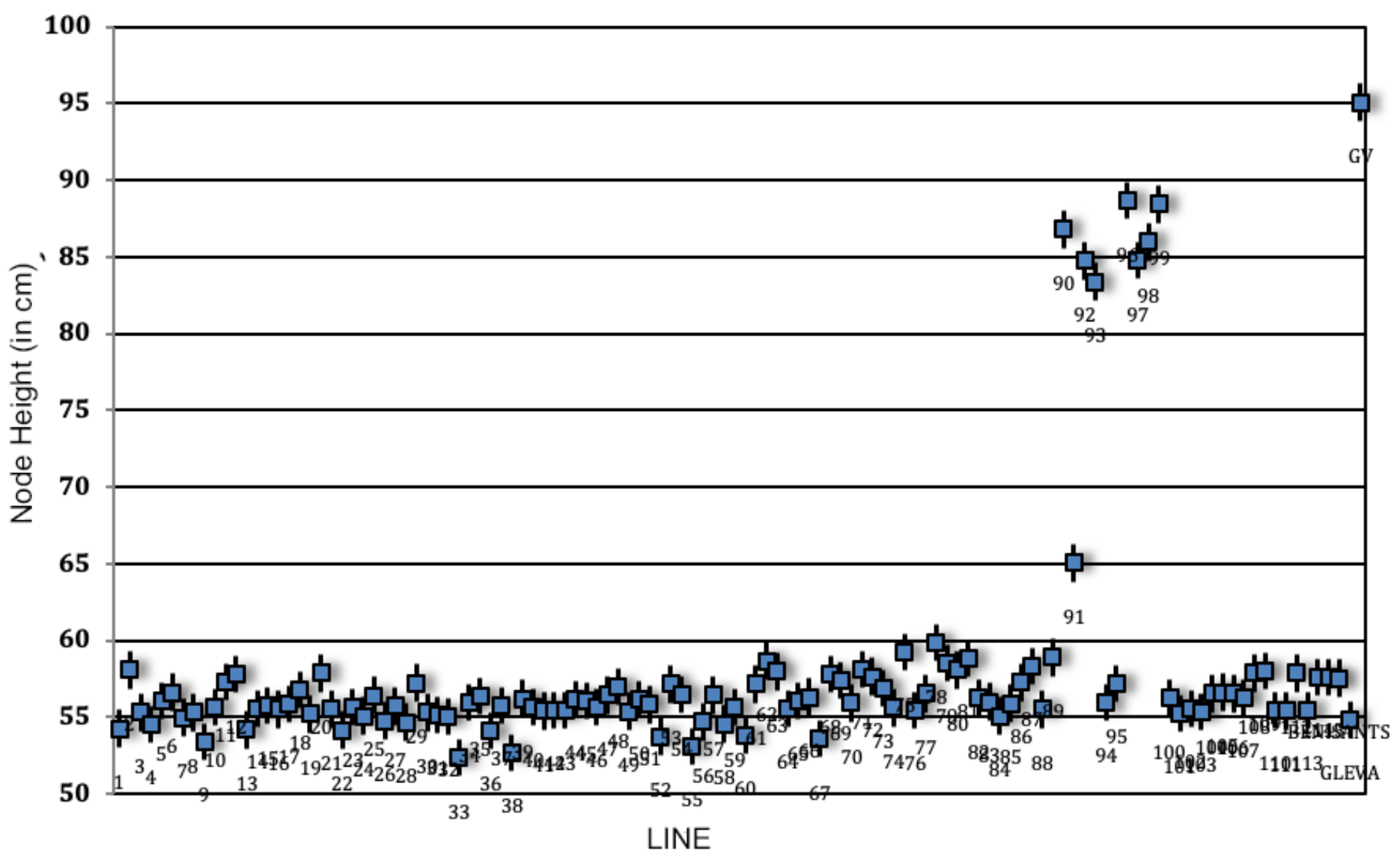

Figure 2

Proximity dendogram $(\mathrm{NJ})$ built using the estimated genetic distance among the 115 Double haploid lines (DHL) and their two parentals, 'Benisants' (BE) and 'Gigante Vercelli '(GV). 


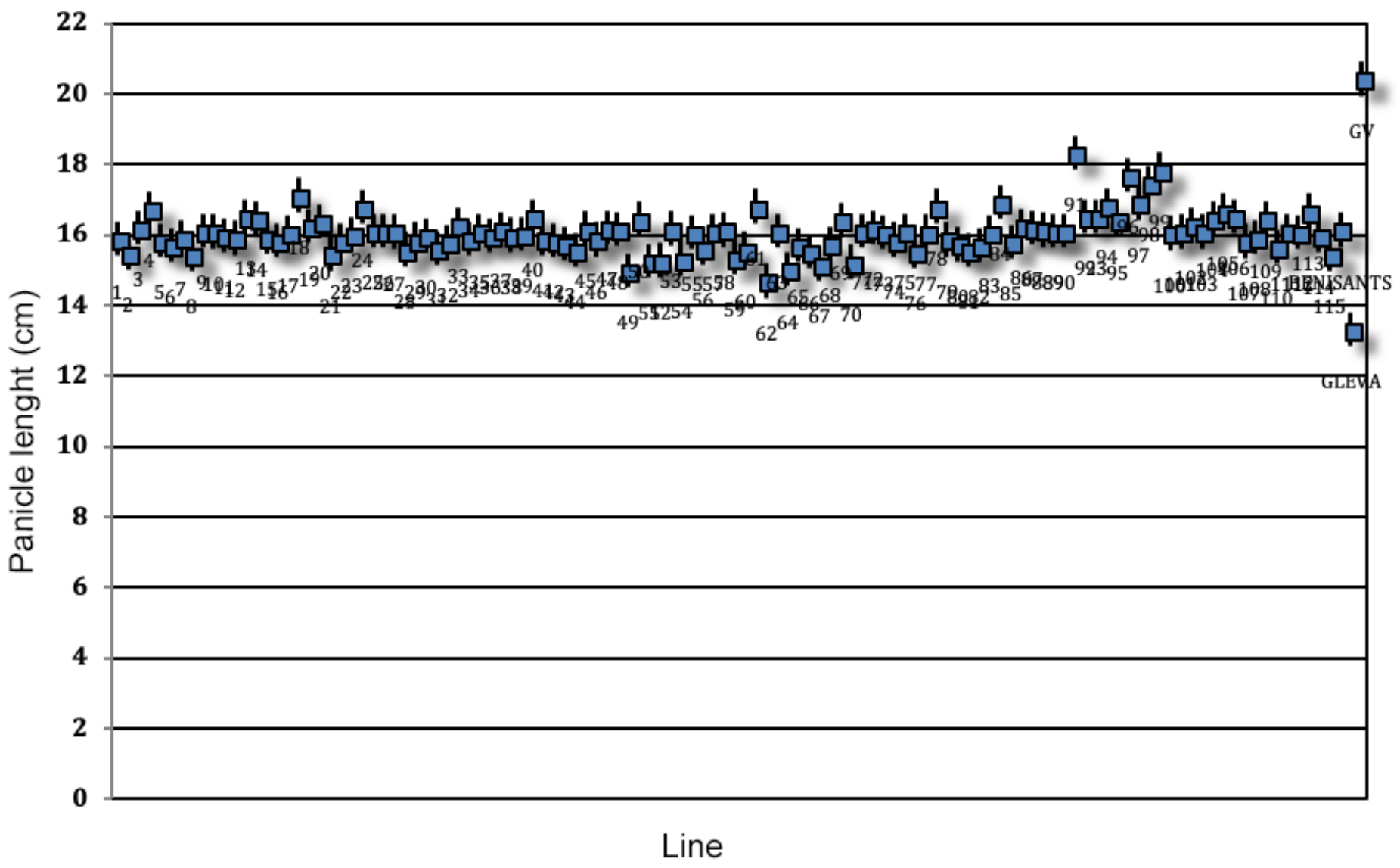

Figure 3

Main panicle length $(\mathrm{PL})$ of the 115 rice DHLs, their parentals 'Benisants' and 'Gigante Vercelli', and the reference variety 'Gleva'. Bars indicate standard error of diference. 


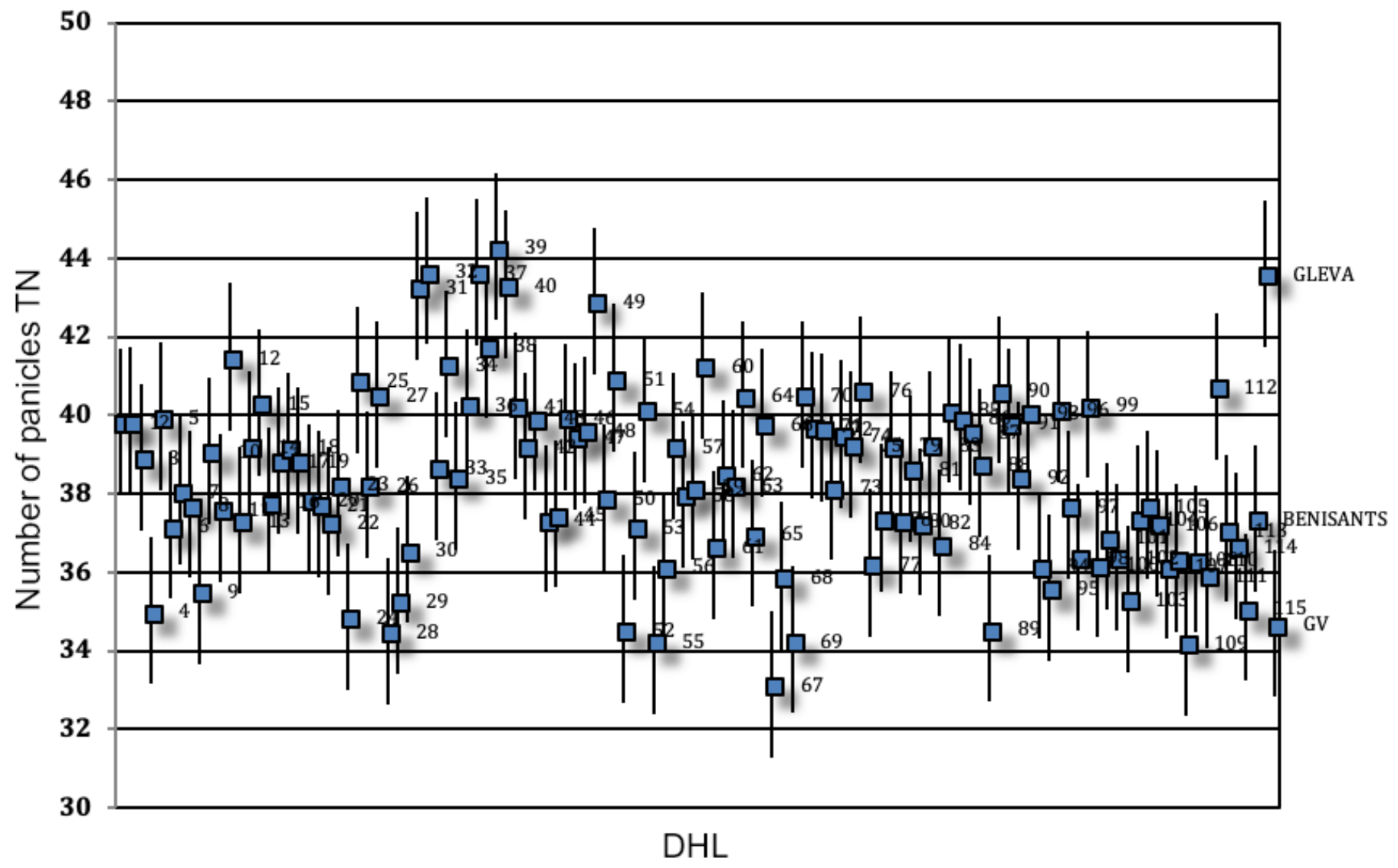

Figure 4

Number of panicles (PN) of the 115 rice DHLs, their parentals 'Benisants" and 'Gigante Vercelli,' and the reference variety 'Gleva'. Bars indicate standard error of diference. 


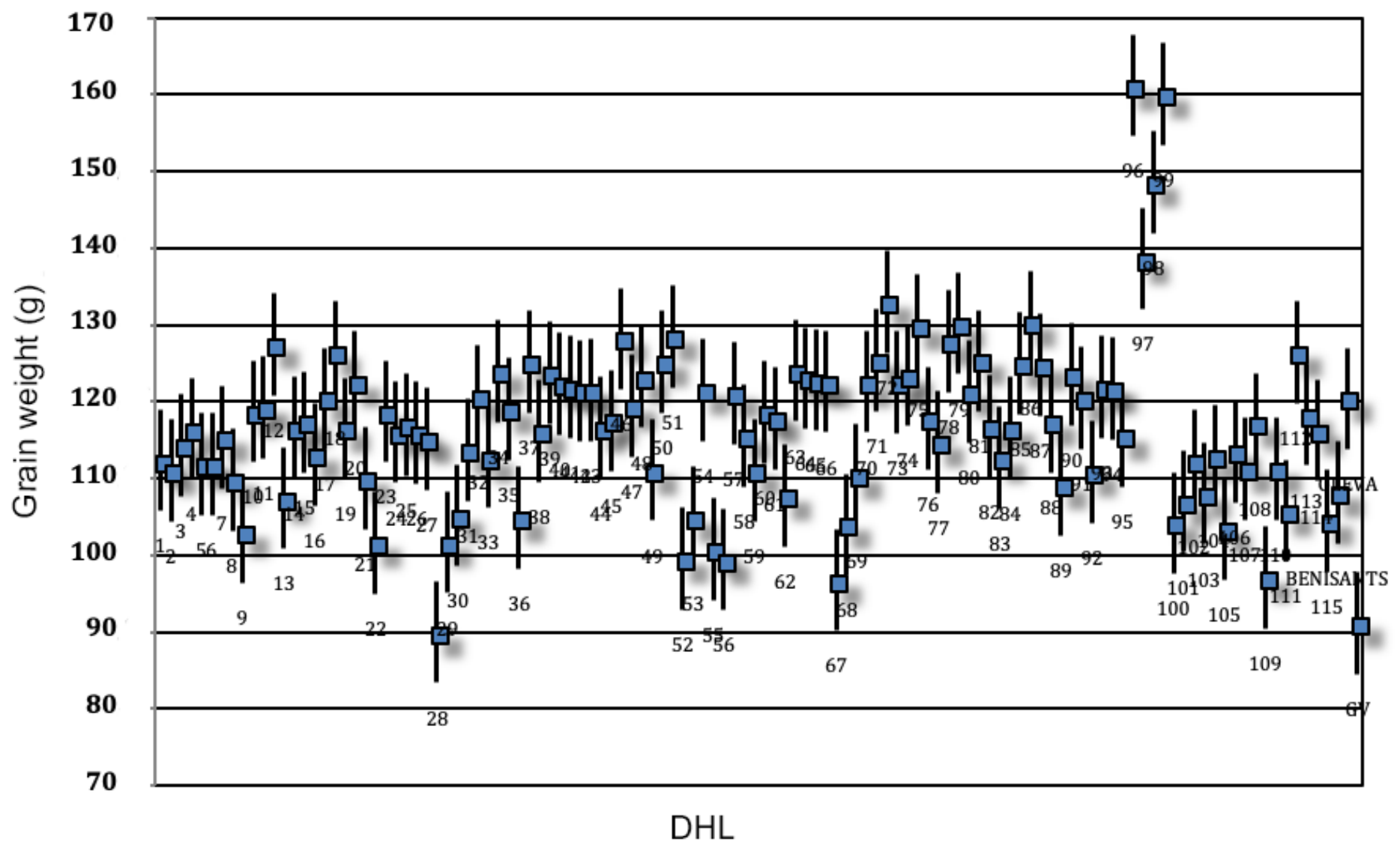

Figure 5

Grain weight per plant (GW) of the 115 rice DHLs, their parentals "Benisants" and 'Gigante Vercelli,"and the reference variety "Gleva". Bars indicate standard error of diference. 


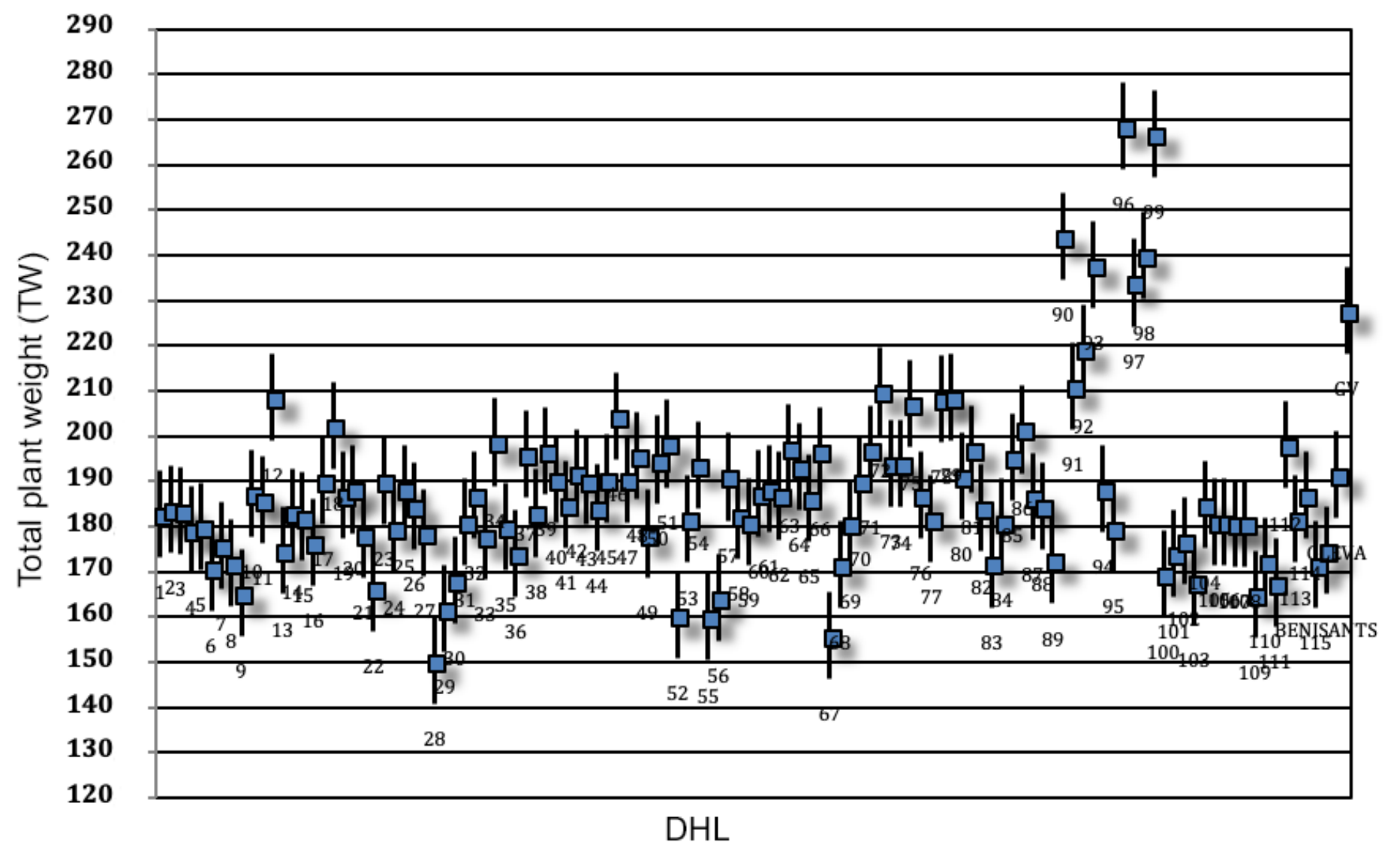

Figure 6

Total plant weight (TW) of the 115 rice DHLs, their parentals 'Benisants' and 'Gigante Vercelli,' and the reference variety 'Gleva'. Bars indicate standard error of diference. 


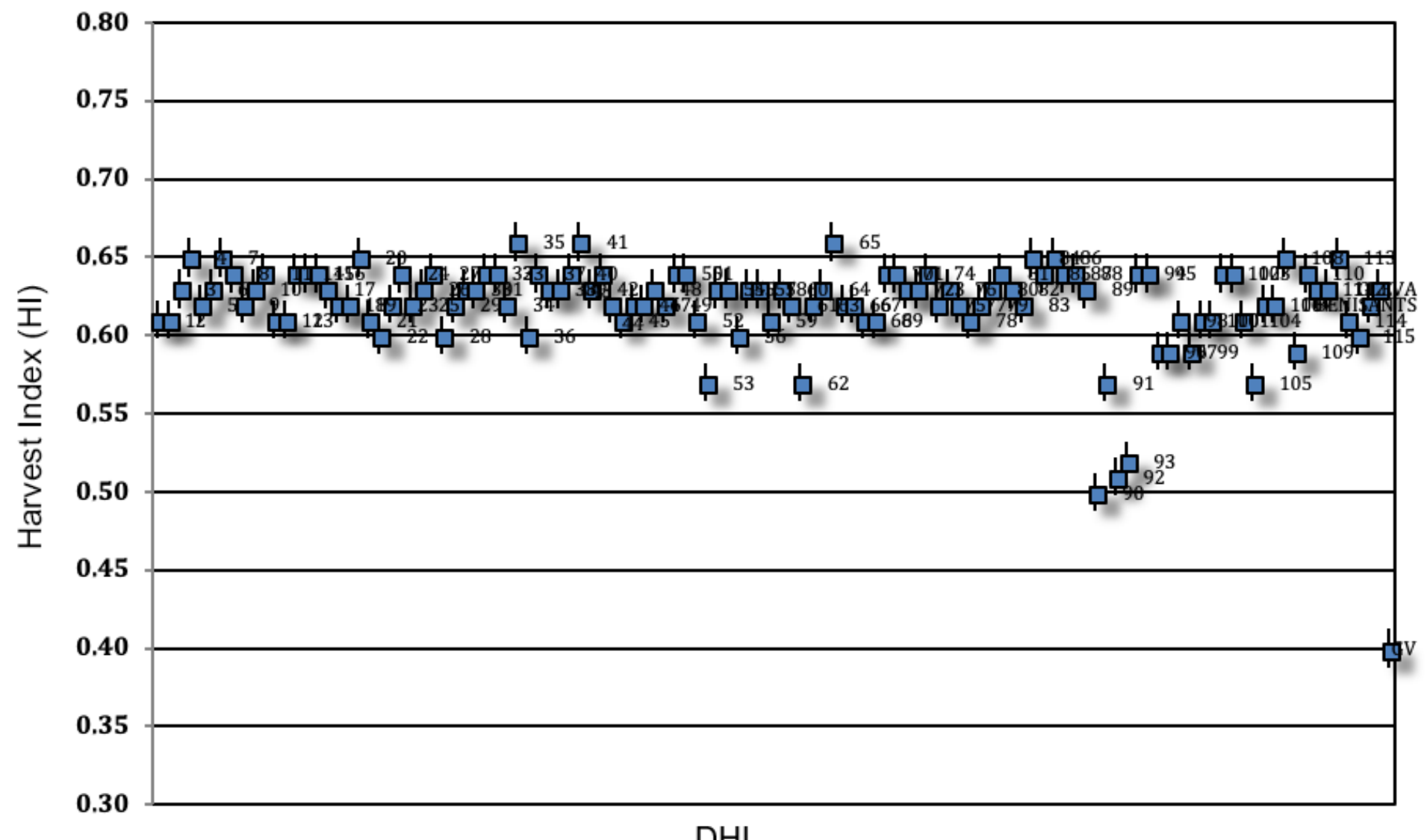

Figure 7

Harvest Index (HI) of the 115 rice DHLs, their parentals 'Benisants' and 'Gigante Vercelli,' and the reference variety 'Gleva'. Bars indicate standard error of diference. 


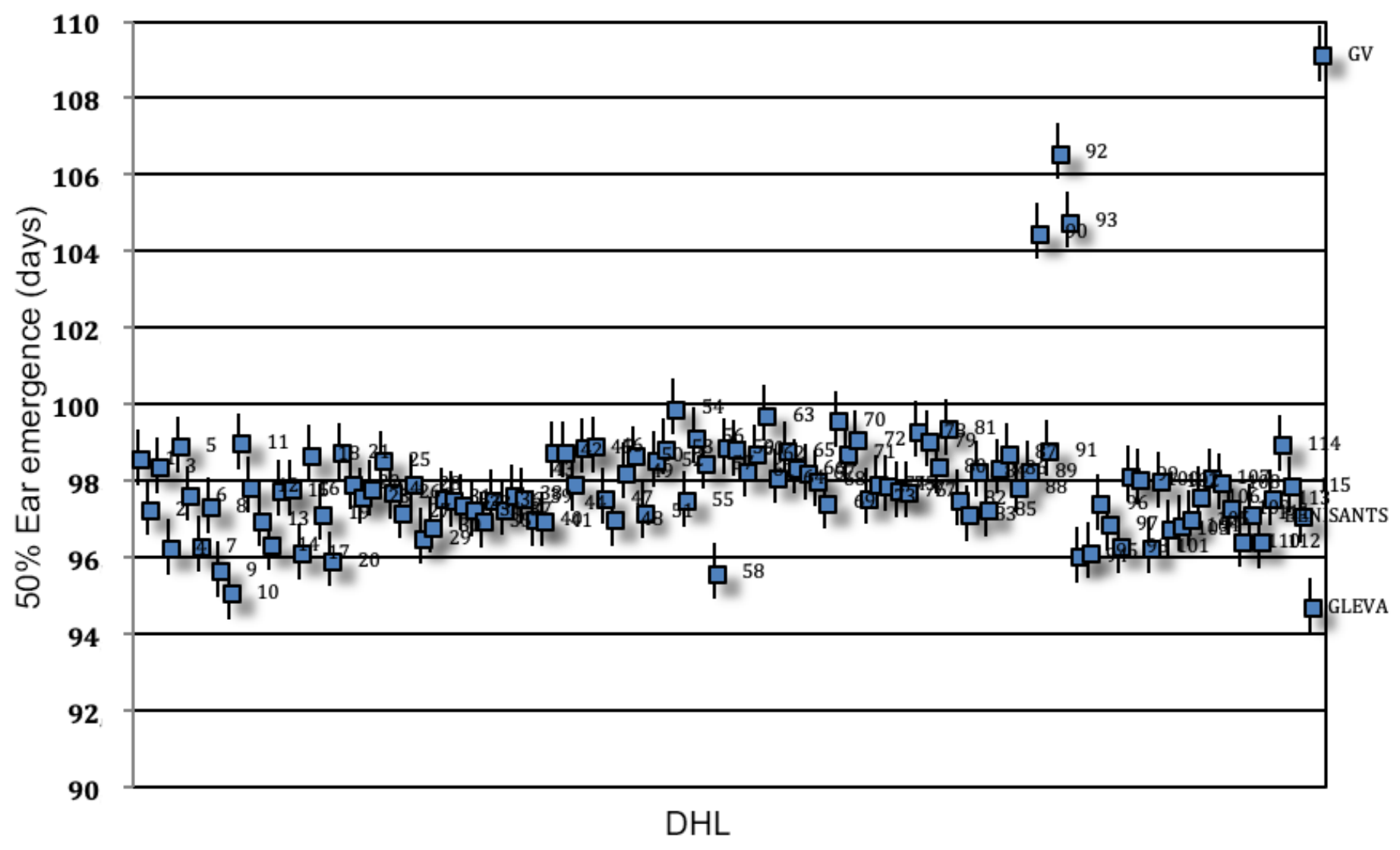

Figure 8

Days until 50\% ear emergence (DE) of the 115 rice DHLs, their parentals 'Benisants' and 'Gigante Vercelli,'and the reference variety 'Gleva'. Bars indicate standard error of diference. 


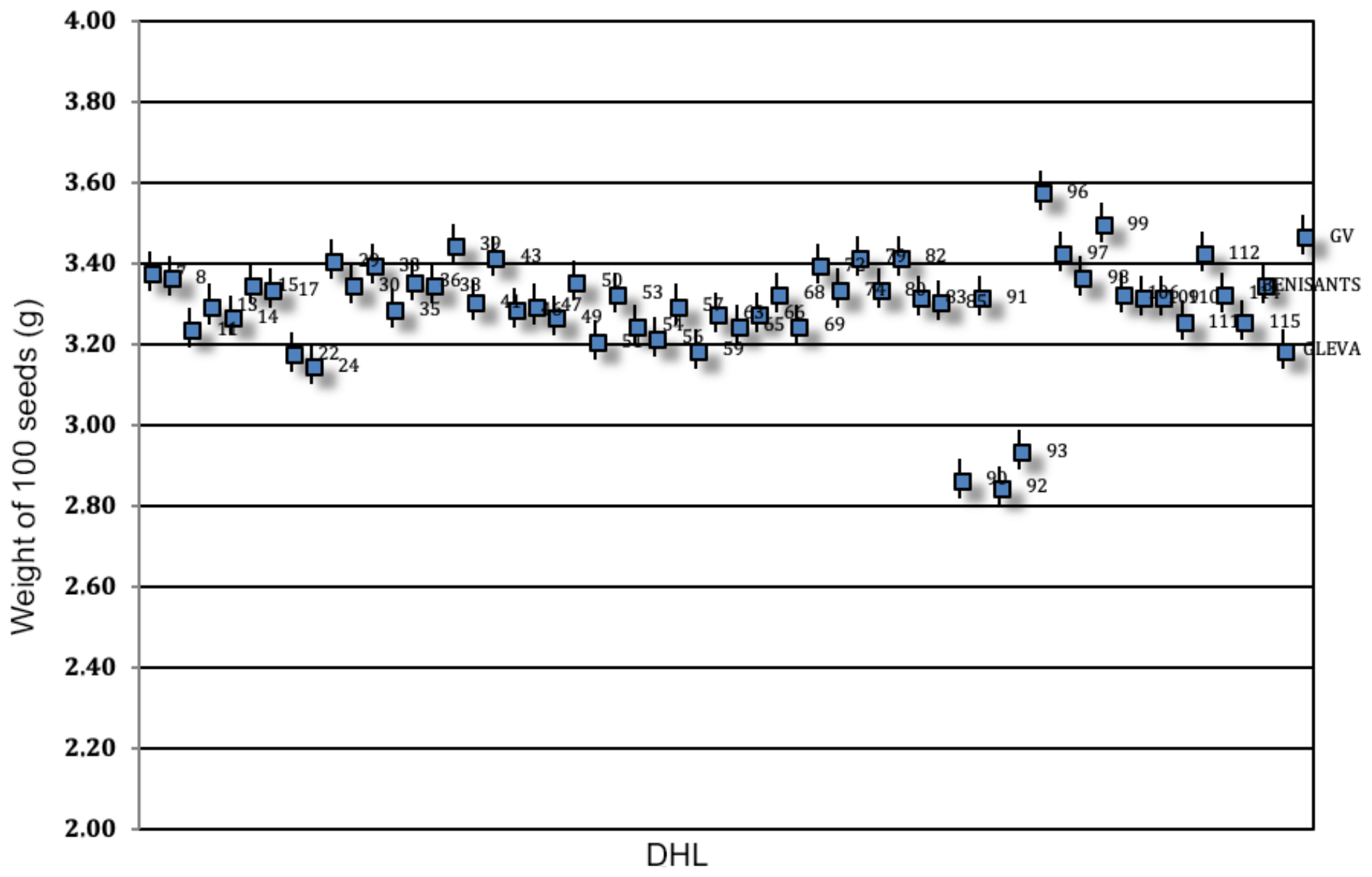

Figure 9

Weight of 100 grains (W100) of the 55 rice DHLs, their parental "Benisants" and "Gigante Vercelli," and the reference variety "Gleva". Bars indicate standard error of diference. 


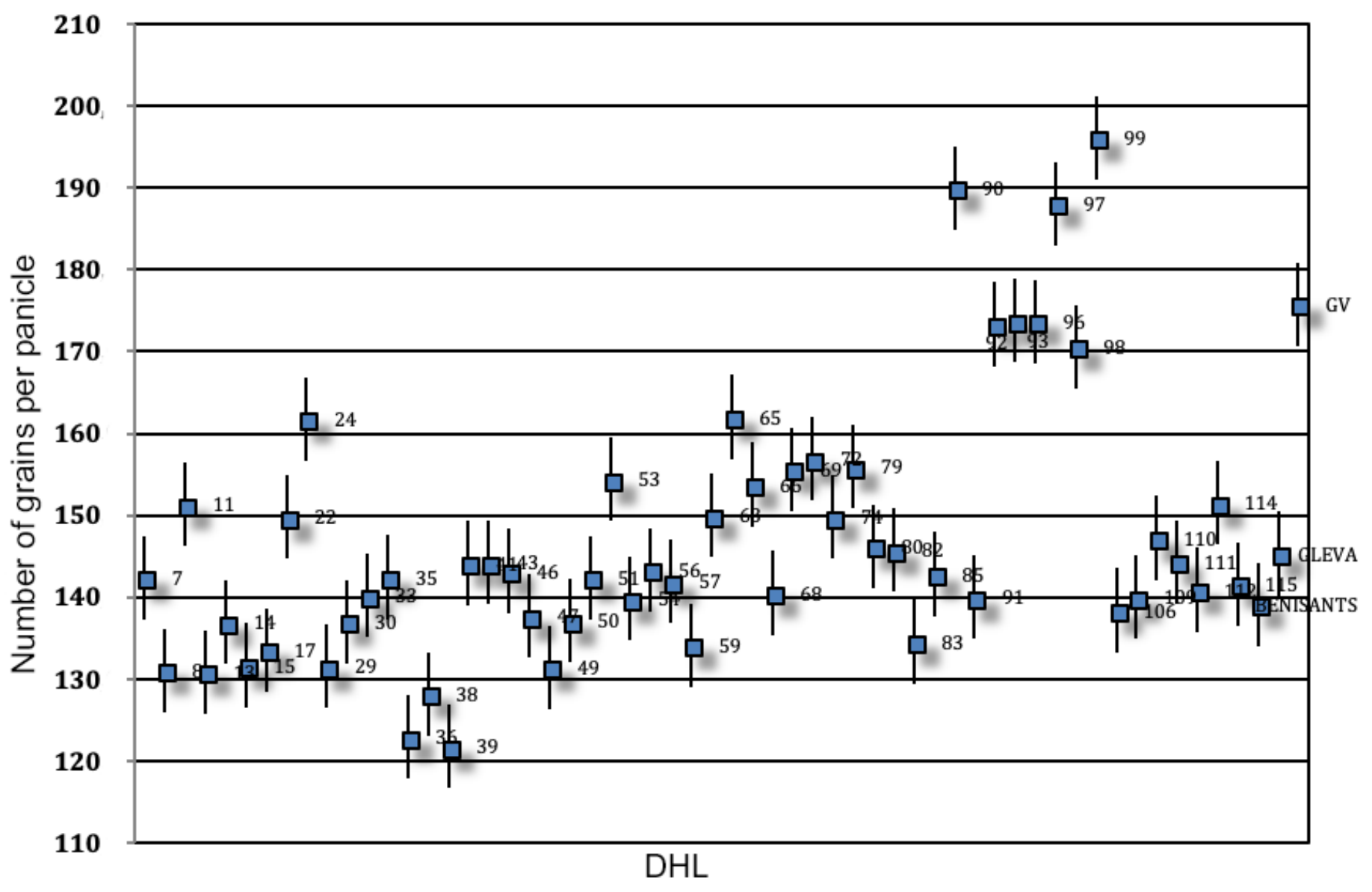

Figure 10

Number of grains per panicle (NGP) of the 55 rice DHLs, their parental 'Benisants' and 'Gigante Vercelli,' and the reference variety 'Gleva'. Bars indicate standard error of diference 


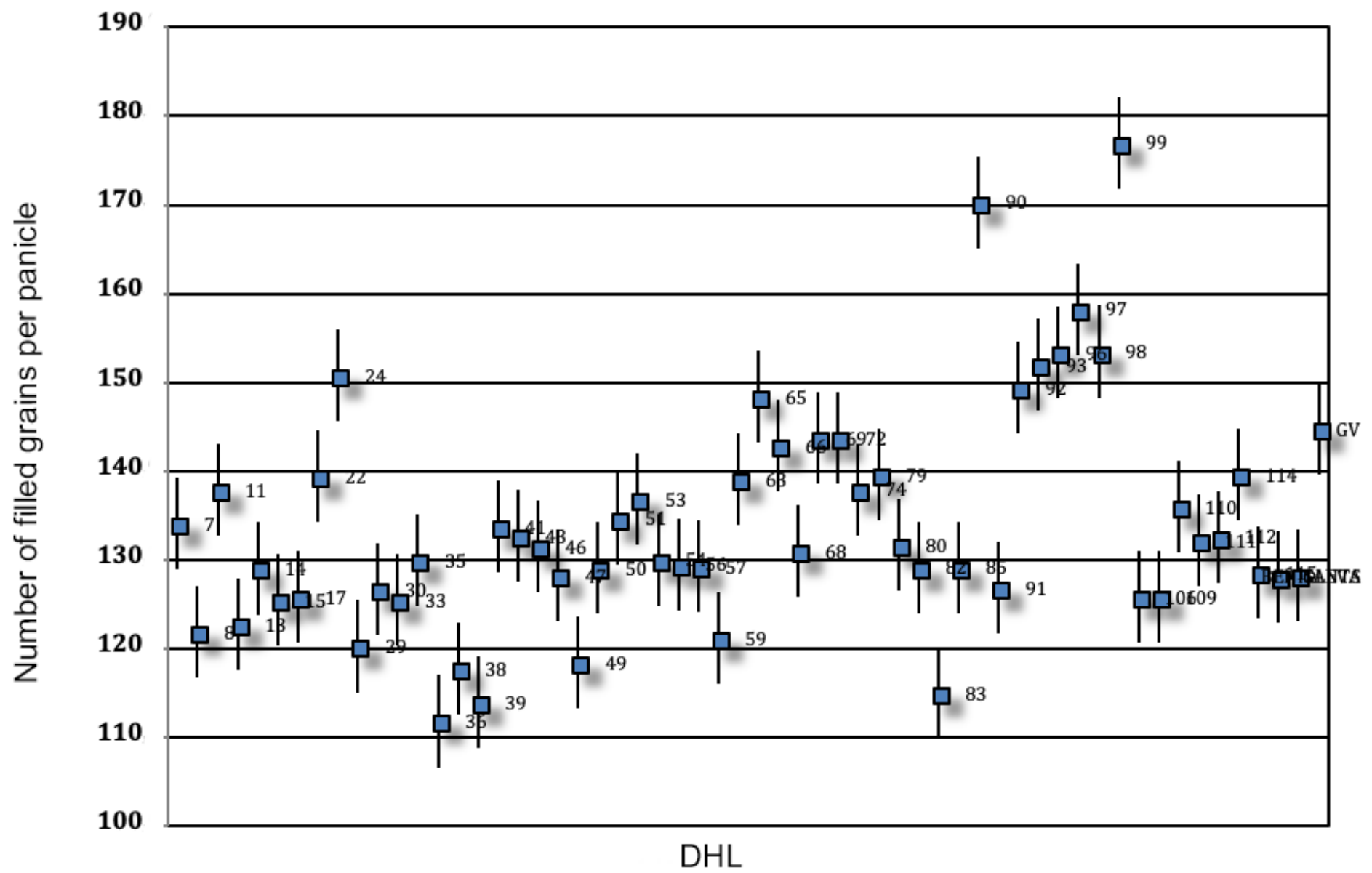

Figure 11

Number of filled grains per panicle (NFGP) of the 55 rice DHLs, their parental 'Benisants' and 'Gigante Vercelli,' and the reference variety 'Gleva'. Bars indicate standard error of diference. 


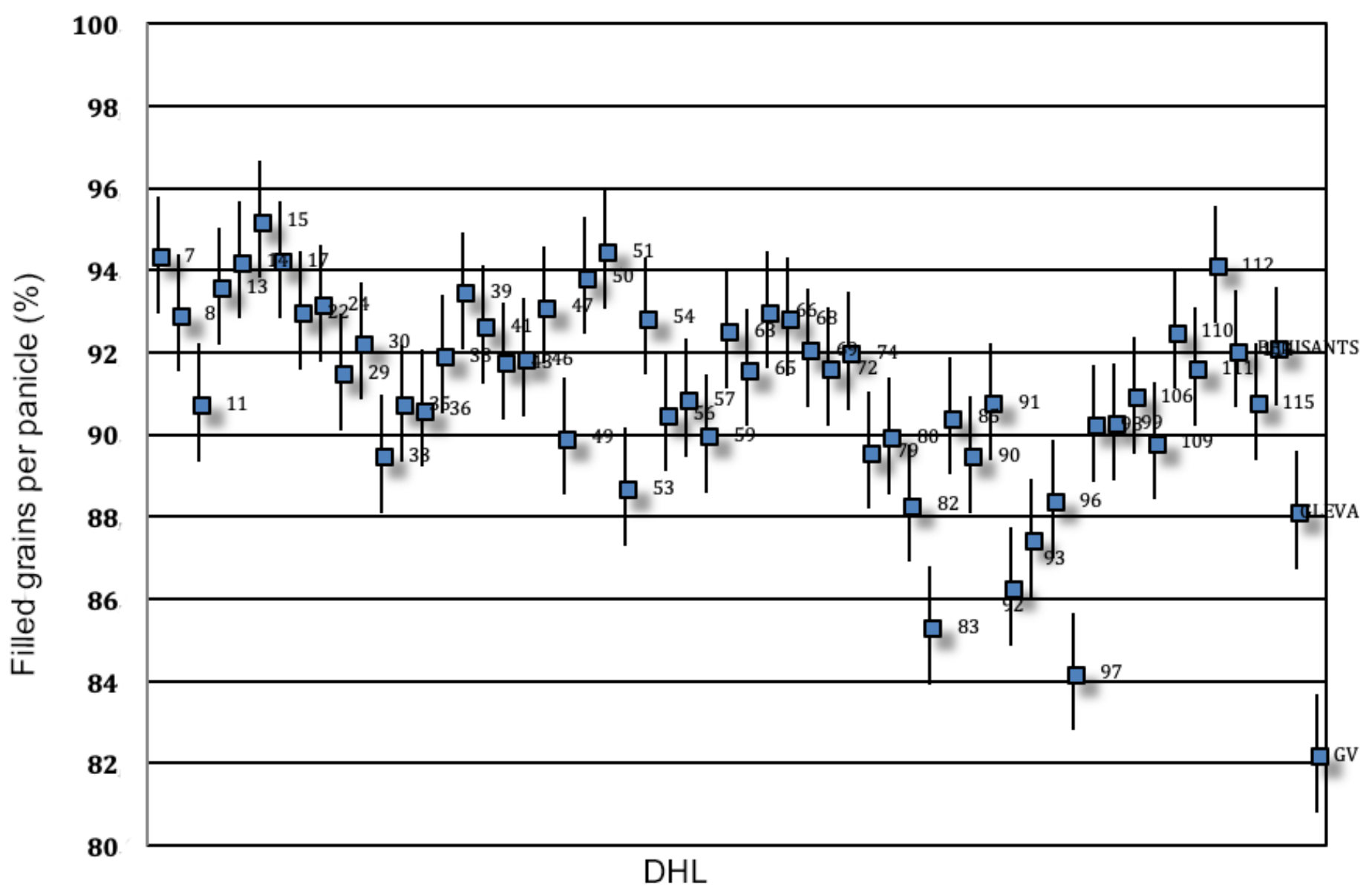

Figure 12

Percentage of filled grains per panicle (\%FILL) of the 55 rice DHLs, their parental 'Benisants' and 'Gigante Vercelli,' and the reference variety 'Gleva'. Bars indicate standard error of diference. 


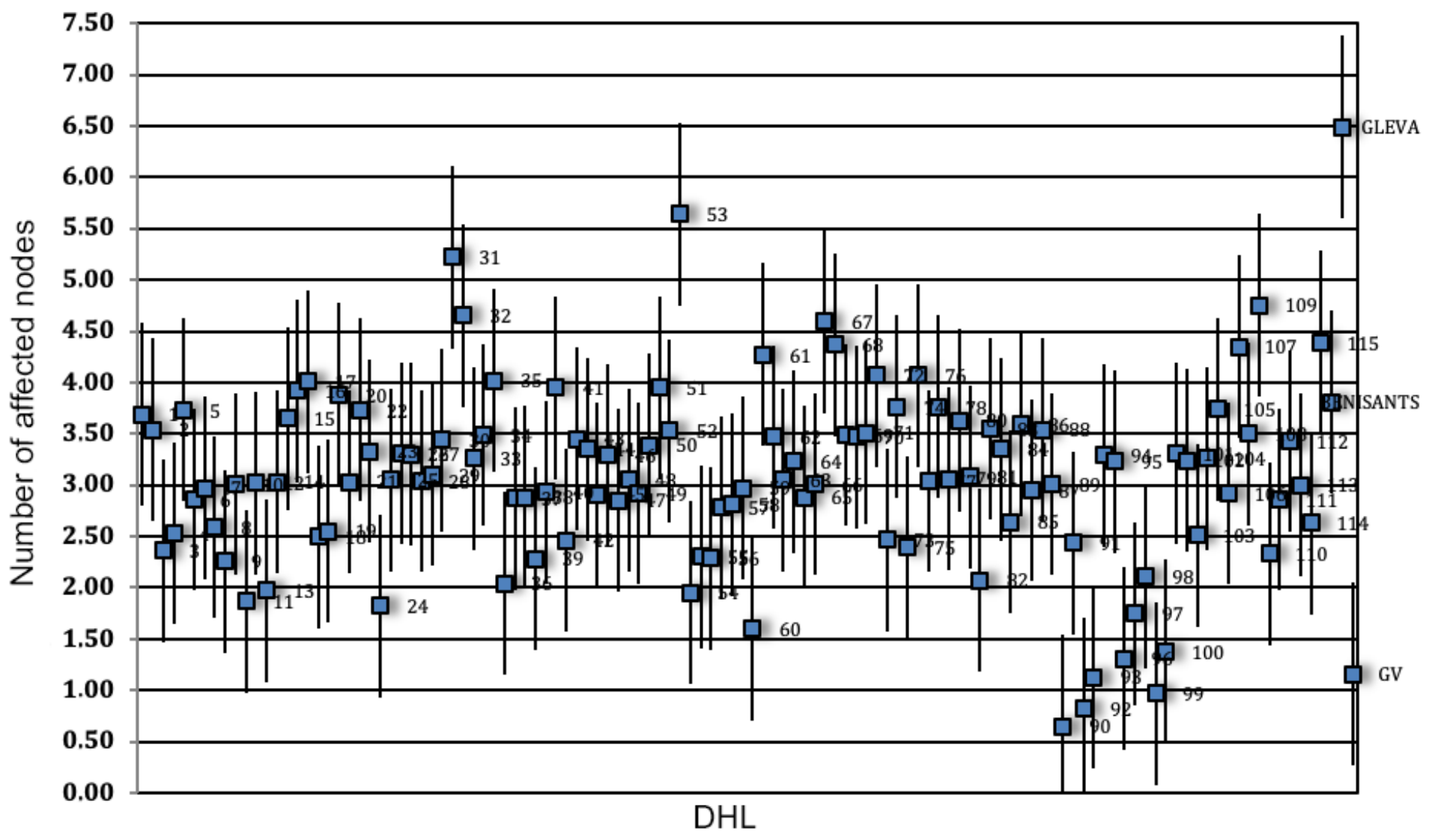

Figure 13

Mean values of the number of the main panicle nodes affected by Pyricularia in 2010 of the 115 rice HDLs, their parentals 'Benisants' and 'Gigante Vercelli', and the reference varity 'Gleva'. Bars indicate standard error of diference. 

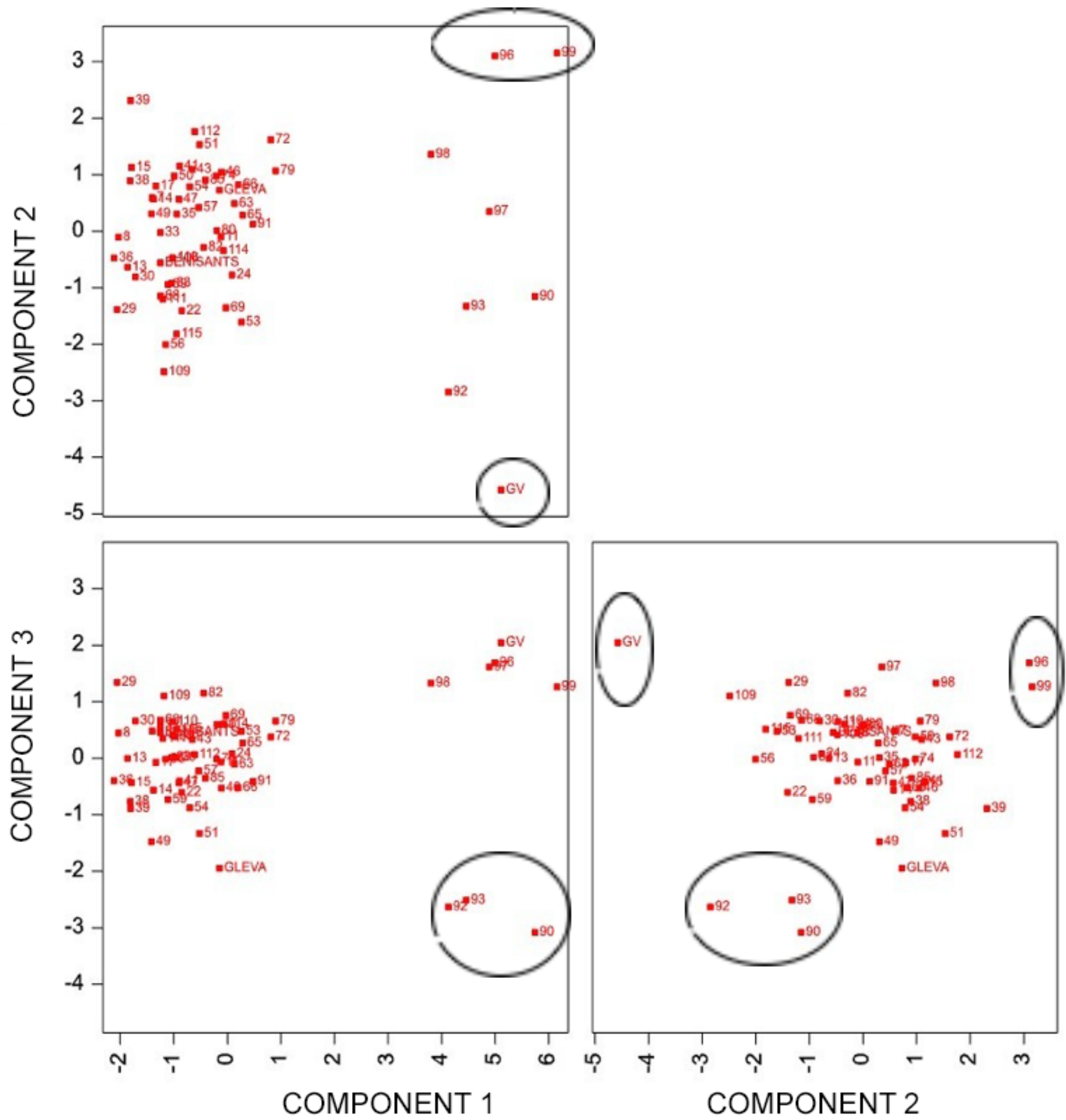

Figure 14

Dispersion diagram of the Principal Components Analysis in the subpopulation with 55 lines compared to the three principal components 


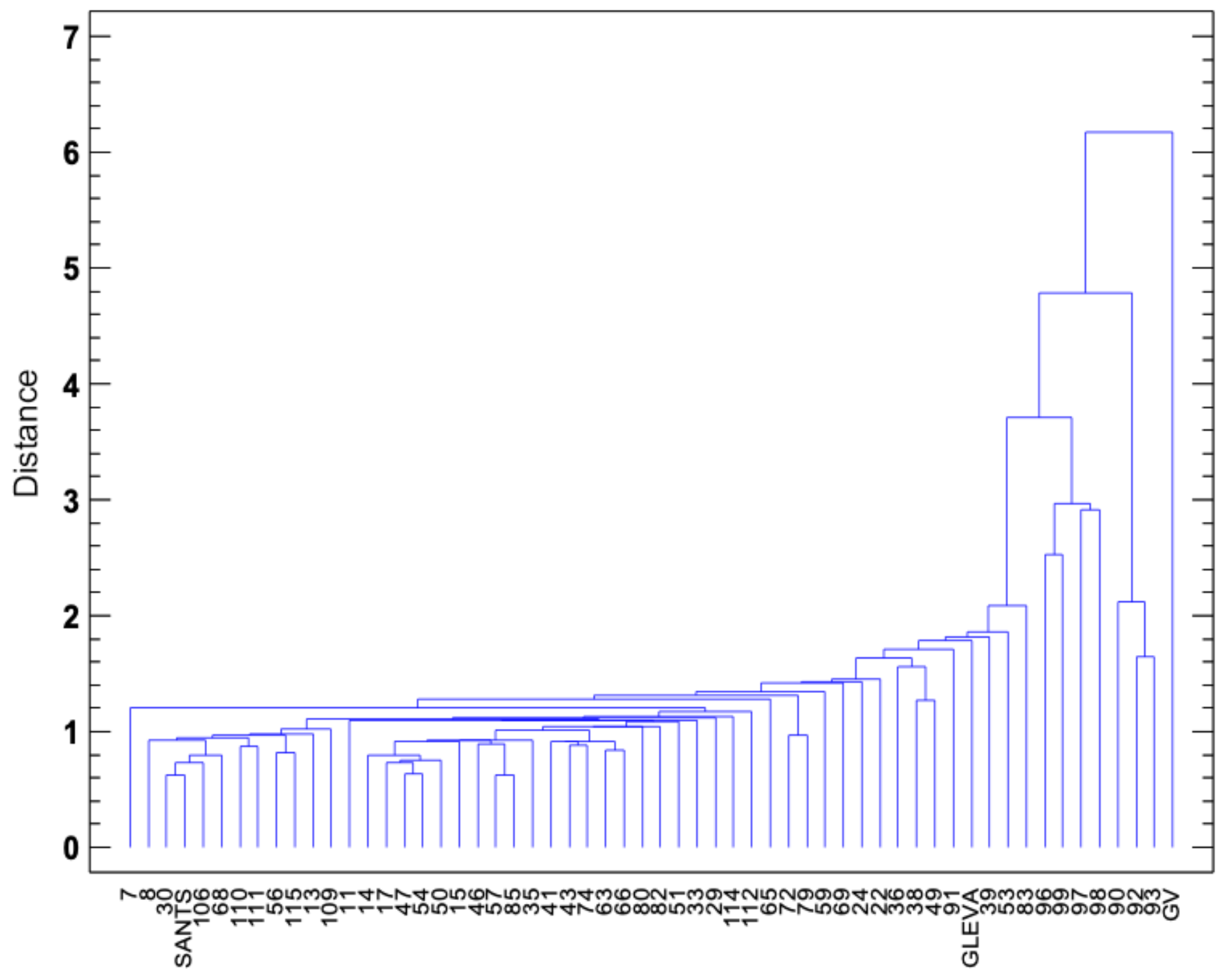

Figure 15

Cluster analysis results obtained with all the morphological characters evaluated during the 2009 and 2010 field trials. 